Article

\title{
Fisheries Sustainability through Soft Multi-Use Maritime Spatial Planning and Local Development Co-Management: Potentials and Challenges in Greece
}

\author{
Stella Sofia I. Kyvelou *D and Dimitrios G. Ierapetritis \\ Department of Economic and Regional development, Panteion University of Social and Political Sciences, \\ 17671 Athina, Greece; d.ierapetritis@panteion.gr \\ * Correspondence: kyvelou@panteion.gr; Tel.: +30-210-9221066
}

Received: 10 February 2020; Accepted: 3 March 2020; Published: 6 March 2020

check for updates

\begin{abstract}
Small-scale fisheries in the Mediterranean represent a significant part of the fisheries industry and their substantial social, economic and place attachment related role has always been acknowledged in the region. Despite the fact that this usually family-based endeavor has a vast economic impact on coastal and island communities of the sea-basin, data and insights on the Mediterranean artisanal fisheries continue to be inadequately developed and poorly integrated in the local development strategies. Thus, the aim of this research is two-fold. Firstly, it presents some data and facts on the fisheries sector in the region and secondly it explores the options of their survival, prosperity and sustainability, approaching the combination of fisheries and tourism as a small-scale and soft "multi-use" in the marine space. Greece, with a huge potential in both the fisheries and the tourism sector, was used as focus area where a co-development process was designed aiming to identify advantages/potentials and challenges/disadvantages of the co-existence of artisanal fisheries and tourism, as perceived by a series of stakeholders including the co-management schemes (Fisheries Local Action Groups, FLAGs) in the country. Key conclusion is that sustainable livelihood from small-scale fisheries depends on the correlation between fisheries and other marine activities. Despite some limitations, this can boost sustainable local development and be a unique pattern of a "win-win" and soft multi-use marine spatial planning (MSP), with economic, environmental, social, cultural and governance related benefits for the coastal communities.
\end{abstract}

Keywords: sustainable fisheries; tourism; fishing tourism; Maritime Spatial Planning; multi-use; local development; local entrepreneurship; coastal/island communities; Mediterranean; Greece

\section{Introduction}

In the last decades, the fisheries sector experiences serious constraints, such as the shrinkage of fish stocks due to overfishing, the shortages of competitiveness, specific European Union (EU) regulations for decreasing discards and unnecessary by-catches, etc. The consequences are lower profitability of the fishing activities and unemployment in the fishing sector [1]. For all these reasons, it is well acknowledged that the fishing activities should be broadened by aiming on innovation and diversification [1,2]. In particular, small-scale fisheries are a multi-dimensional activity that ensures food from the sea is connected to land-sea interaction, and is (strongly) socially, culturally and symbolically rooted in the local communities. It has been observed [3] that small-scale fisheries beyond the SDG14b exclusively dedicated to this activity, which appeals for providing to small-scale fishers access to resources and markets, can obviously have a major weight in a series of Sustainable Development Goals (SDGs). For example, offering food security (SDG1), alleviating poverty (SDG2), providing gender equality (SDG5) and finally linking to community wellbeing (SDG3) and promoting economic growth (SDG8). 
On the other hand, the EU encourages the multi-use (MU) in the sea space, that is the combination of several sea uses so as to share and reduce the costs of offshore operations and regulate the claim on the sea space by different activities [4,5]. Multi-use (MU) of marine space is defined as a "joint intentional use of resources in close geographic proximity ... this can involve either a single user or multiple users" [4]. Despite reservations stated in the literature about the complexity of multi-use (MU), this is a smart and attractive option for marine planners and stakeholders pursuing to reduce conflicts of different sea uses [5]. Stakeholders appear to be willing to co-locating activities [6], though each distinct combination demands special measures, practices and settings, due to the particular nature of the activities concerned [7], e.g., artisanal fishing often runs the risk of being displaced and this has to be faced through clever and innovative mutual arrangements. Based on an analysis of operating boundaries of several activities, van den Burg et al. [8] determine the highest potential for the multi-use of sea space to be within 16 nautical miles from the coastline and with a depth less than $100 \mathrm{~m}$ [8]. This is particularly significant for fisheries that are from their nature, related to the land-sea interface.

Through the vast multi-use related literature [4-8] it is evident that there are differences between Northern and Southern European countries. The North specializes in offshore wind farming and renewable ocean energies as key drivers of blue growth and MU sectors, and the South, with tourism being its main and robust income source, presenting predominantly a trend to create smart, small-scale and soft [9] co-locations of both traditional and emerging maritime economic industries. In this framework, a combination of fisheries, tourism and environmental protection in European seas are reported to be concentrated on the French Atlantic coast [10] and in the Mediterranean [11], with emphasis in the Northern Adriatic Sea. Specifically, in European research projects $[4,10,11]$, the combination of tourism and fisheries was identified through case studies, situated in the Eastern Atlantic and in the Mediterranean Sea basins, with the North Adriatic and the Aegean Sea being the prevailing hot spots. In all these cases, the tourism-fisheries co-existence is labelled as "pescatourism" or simply fishing tourism. This is commonly defined as the embarking of tourists on small-scale fishing boats for recreational and cultural purposes. Professional small-scale fishers play a central role in promoting and educating tourists on the environmental, socio-cultural and economic values of their islands or coastal areas by presenting them fishing methods and optionally by offering them local gastronomic satisfactions on board.

This research article approaches fisheries and tourism as a "multi-use" marine spatial planning (MSP) setting in the Eastern Euro-Mediterranean, focusing on the analysis of the situation in Greece, a country that is well-developed in both the concerned sectors, that is fisheries and tourism as well. These two activities are among the main drivers for blue growth as reaffirmed also by regional and local stakeholders that ensure co-management in the fisheries sector [12] as Fisheries Local Action Groups, in recent blue growth-related research [13]. The article examines the status of fisheries and of the co-management schemes (Fisheries Local Action Groups, FLAGs) established in the country, and explores the potentials of such an activity and the barriers that should be overcome to make MU settings-especially fishing tourism—catalysts for livelihood opportunities in coastal and island communities. It also considers fishing tourism in the framework of Maritime Spatial Planning, assuming that the combination of sea uses, such as "fisheries-tourism-environmental protection" can be a unique pattern for a "win-win" multi-use MSP in the Eastern Mediterranean [5] with economic, environmental, social and cultural benefits for the coastal communities. This can be particularly relevant in small sea spaces [14], closed or semi-enclosed seas that are peopled and crowded [5], and present great institutional fragmentation and conflicts between economic and environmental stakeholders and uses.

The fishery and aquaculture sectors in Greece present higher rates than in the total of the EU member states, contributing stably by $0.4 \%$ to the national GDP, and the per capita production of Greek fishery and other products is larger than the respective production worldwide. Greece is amongst the five EU member states that produce three quarters of the total aquaculture production, both in quantity and in value. However, overfishing in combination with competition with amateur and retired fishermen, reduced catches value and loss of consumer purchasing power-due also to the economic 
crisis and the concurrent austerity measures-are factors that increasingly shrink fishing income and push Greek fishermen either to abandon the activity or to seek opportunities of supplementary income sources. It is in this context, of local development, pursuit of employment and livelihood opportunities through also co-management in fisheries, that this research article is embedded.

\section{Background of the Research}

\subsection{About the Sustainability of the Fisheries Industry in the Mediterranean}

Fishing is considered one of the main engines of sustainable development in the Eastern Mediterranean Sea-basin, both for its societal dimension and its economic influence, especially at a local level. A key requirement for the sustainable development of fisheries is the current and prospect well-being of both the bio-ecological and human systems and the correspondent management process [15].

The broader Mediterranean Sea is the major semi-enclosed sea in Europe, modest in nutrients, rich in oxygen and with higher salinity compared with other European seas. Its heterogeneity and sequestration have engendered numerous habitats resulting to a rich biodiversity. Fisheries is among the ecosystem services provided and maintained by the biodiversity. The fishing fleet of the Mediterranean counts approx. 82,000 vessels, with $80 \%$ being of small-scale. Total reported landings fluctuate around 800,000 tonnes, mainly focused in the western Mediterranean and the Adriatic Sea and the sector delivers about 314,000 direct jobs [16]. The Mediterranean coastal areas host a series of human activities, which are essentially responsible for the deprivation of marine ecosystems and key constraints are the severe decline of the fish stocks and the many spots of pollution especially where human intensity is heavy and waste management is inappropriate. Other burdens are the heavy maritime traffic, the climate change related vulnerability, which means expected moves of species, alterations and imbalances between the fish populations and arrival of new invasive species.

So far, the EU is using anticipatory techniques and methods presenting long-term effects with concrete examples being the EU multiannual plans or the General Fisheries Commission for the Mediterranean (GFCM) management plans [17]. However, it is commonly accepted that in order to inverse the constant deterioration of fish stocks, the unanimous adoption of immediate and specialized measures of both European and global scope, is needed by all the countries bordering the Mediterranean. Considering both economic and ecological risks, this is recognized as a key success factor.

Fish stocks are exploited almost entirely by EU fishing boats in the north-western Mediterranean and in the north Adriatic Sea, whilst the Central and the Eastern Mediterranean (namely the Ionian, the Aegean and the Levantine Seas) are mutually exploited by EU and non-EU member states. Scientific observations agree on the decline of the huge mass of fish stocks and to the possible exhaustion of some of them. It is reported that only a percentage of $9 \%$ of fish stocks are exploited in lower quantities than the Maximum Sustainable Yield (MSY) and that there is still no sufficient information about the status of a large amount of fish stocks [18]. Particularly for some kinds of fish stocks, the fishing mortality rates far exceed the MSY. The volume of these species represents about $43 \%$ of the overall catches by the EU fishing vessels $[19,20]$. It is, besides, very common for fishermen to complain about the fact that their catches become more and more unavailable, which means a low performance for the fisheries sector and serious negative impacts on the overall economy, inherent sense of place, identity and even survival of the coastal and island regions.

There are numerous causes for the humble state of fish stocks such as marine litter, climate change related impacts and extensive overfishing. A number of techniques has been initiated by the EU to control overfishing. Thus, EU member states have been asked to diminish their vessels and legislative measures include management plans on national and global level, catch controls and conservation requirements. Besides, the countries bordering the Mediterranean Sea are urged by international cooperation organizations and Integrated Maritime Policy (IMP) facilities to keep on analogous rules [20]. Cooperation at regional and sub-regional scales is also recommended [21] with 
the aim to develop advanced models (e.g., fishing lower trophic level species, giving large areas to recreational fisheries and to marine protected areas). Furthermore, controlling juvenile exploitation, progressing management plans, and enhancing compliance, controlling and enforcement mechanisms are judged absolutely necessary to promote fisheries sustainability in the Mediterranean [22]. However, it is commonly accepted that further actions and efforts are required. To prevent the shrinkage of fish stocks and its negative impact on the marine ecosystems and ensure the sustainability of the fisheries industry in the Mediterranean, all countries bordering the Sea Basin need to act urgently and in a collective and coordinated manner [18,21].

\subsection{The Contribution of the Fishing Tourism to Local Development}

"Pescatourism" has a rather long history with the term appearing in Italy in 1992 and originally used in the Italian legislation to denote the boarding of non-fishermen adults, aged over 14, on fishing boats with a recreational or tourism commitment [23]. Prosperi et al. [24], define it as "the activity of a fisherman, a fishing company or a fishing cooperative aiming at transporting non-crew members, such as tourists, and conducting recreational activities" [24]. Today, pescatourism is developed in various Mediterranean countries as an alternative to coastal tourism [25], involving the provision of services usually by small-scale fishermen, who invite tourists on their vessels in order to introduce them to the local fishing tradition in combination with educational and recreational activities. In support of the above, it was revealed [11] that there is also a strong correlation between fisheries tourism and marine ecosystem protection, either as a pescatourism activity occurring near or within marine protected areas (MPAs) in an eco-tourism context, or fostering initiatives involving environmental/ecosystem-based education.

Fishing tourism's contribution to local development of European coastal areas is essential: it is a form of alternative tourism based on traditional activities, which can attract visitors seeking authentic experiences, such as artisanal fishing [26]. Through the enrichment of the locally offered tourism product, the local tourism entrepreneurship and the local labour market are enhanced [24], while at the same time, an alternative additional income is offered to local fishermen/entrepreneurs, who by exploiting their already available skills and means, can develop new activities and offer recreational and educational services to tourists. Moreover, they may expand the additional income sources by offering hospitality services to the tourists desiring to spend one or more days at the fisherman's residence and participate in their everyday routine (housework, preparation of the fishery products for trading, preparation of the fishing gear, such as nets, baits, etc.). This is a type of tourism service already offered in the Italian coastal areas, referred to as itti-tourism (itti-tourismo) [23]. The advantages of pescatourism for the fishing income also include the expected increase in local demand for locally caught fish, which are sold to the retail market, restaurants, etc. Moreover, an important (yet not readily noticeable) contribution of pescatourism to local development is the enhancement of the local identity and the social status of the fishermen themselves. Besides, their role in the consultation and planning of tourism development strategies, or initiatives for their coastal/island area is also improved [27].

Since the practice involves a daily journey on a fishing vessel—with indigenous fishermen hosting tourists aboard and guiding them to join the fishing operations, along with participating in gastronomic satisfactions, or offering stay in their villages to make them share their daily life-a positive aspect is that throughout this activity, the conditions may be shaped for a shared vision between tourists and indigenous people. Inhabitants are usually motivated to safeguard their living environment, in terms of environmental, economic, social or cultural goods, avoiding or mitigating destructive tourism impacts. Tourists, have instead, the chance to discover the geography and cultures of places, landscapes and seascapes, through direct involvement in a traditional activity, practiced by Mediterranean coastal or island communities.

In this sense, fishing tourism is also suggested in culture-oriented programmes targeting the diversity of European local cultures and heritage and the nexus between preservation/maintenance and sustainable use of the heritage to the benefit of local populations [28]. Cultivating cultural attitudes of tourists make them also cautious about heritage both natural and cultural, tangible and 
intangible and probably enables them in being part of conservation procedures, thus participating in a learning procedure.

Relevant to the contribution of fishing tourism to local development was the PESCA initiative (New Community Initiative for Fisheries and Fishery-Dependent Zones) that appeared in 1994 [29], which targeted the revitalization of the local economies, efficiently facing declining fish stocks, poor economic harvests, new consumer habits or new trade patterns, reduced employment opportunities or unattractive revenues. It was an attempt to detach the local communities from the harvesting activity [30] and enhance territorial cohesion [31]. To this end, fisheries policy introduced features of regional policy by supporting local development projects indirectly related to the fishing industry, such as fishing tourism, gastronomic activities, fishing related arts and crafts, relevant museums, etc. Particularly, fish workers could profit from training and vocational learning with a view to re-orient their activities also outside the fishing industry.

Later in 2007, the European Fisheries Fund (EFF), in order to encourage sustainable development and improve life quality in coastal areas with a noteworthy (though weakening) fishing activity, stimulated the revitalization of similar to the 1994 PESCA initiatives [29], namely the initiative of Fisheries Local Action Groups (FLAGs) which are classified as co-management schemes [12]. In this context, fishers and harvesting industries are considered key drivers of local development in the fisheries communities. Local development policies and strategies are enriched with regional policy topics, such as technical or social innovation, networking, quality and protection of the environment, environmental management of resources, such as energy and waste, energy efficiency, etc. This initiative stimulated a lot of interest, even if it seems to have limited impact on local development and on the effort to reverse the decline of the fishing sector. The suffering conditions of the Mediterranean coastal and island communities, due to the low economic performance of the fishing industry, is hard to reverse. Nevertheless, what is of paramount importance is the spill-over effect of innovation, best practice and expertise that may generate renewed territorial potentials in areas confronting with comparable constraints. The FLAGs can apparently have a catalytic role in such spill-over procedures.

It this framework, the influence of women to the fishing industry and the fishing community [32] has been fully acknowledged and attracted EU financing for pilot projects initiated in late 1990s. It is well known that the presence of women on board fishing vessels is a rare occurrence, and, therefore, they generally do not qualify as fish workers. Yet, they contribute to fish production, not only as shellfish gatherers, but women play an important role in the processing and marketing of fish products. Furthermore, their participation, in activities within a family-driven business, although often ignored, is critical. The entitlement of spouses of self-employed workers to benefit from the general system for social protection is a long-awaited and merited acknowledgement of their input.

\section{Materials and Methods}

\subsection{The Research Process-Short Technical Methods}

The research carried out for this paper is two-fold, structured around the following steps:

1. An identification of insights about the sustainable fisheries in the Mediterranean, the state of fisheries in Greece and also about multi-use (MU) in the marine space with key focuses on the latest findings about tourism-driven multi-use combinations, especially the triplet "fisheries-tourism-environmental protection".

2. A co-development process to reveal the potential of fishing tourism in the case- study area, namely Greece, a country situated in the Eastern Mediterranean Sea-basin. To this end, a survey was carried out based on structured interviews to different groups of stakeholders (state services, regional authorities, FLAGs, local fishers and their associations, Non-Governmental Organizations (NGOs), academia and experts) in order to detect their multiple perceptions for both the potentials and the many challenges that fisheries-tourism combination is actually facing. 
The Greek case-study was thus based on: (a) desk and bibliographic research, (b) field research, mainly in collaboration with state authorities, to identify key territorial characteristics of fishing tourism in the country and (c) a structured interview-based survey in order to better apprehend the different perceptions of relevant stakeholders and fully discover potentials, but also challenges and barriers that hamper the development of similar activities. To map the FLAGs in the country, the Fisheries Areas Network (FARNET) database (2017), and specifically, the Country Factsheet about Greece was used [33].

\subsection{The Multi-Use Opportunity: Tourism-Driven MU Arrangements and "Fisheries-Tourism" Assemblage.}

The answer to the rivalry over sea space often relies on the existing practice of inclusive sharing of marine space between several activities $[4-8,10,11,34,35]$. As already mentioned, the Horizon 2020 Multi-Use in European Seas (H2020 MUSES) Project [4], having clearly identified all possible groupings of marine uses from a co-location standpoint, defines multi-use of marine space (MUS) as a "joint intentional use of resources in close geographic proximity ... this can involve either a single user or multiple users". The resources can be both products and services that produce value to a single or multiple users (individual persons, groups of people or legal entities) and their nature may be biotic (e.g., fish stock) or abiotic (e.g., oceanic space) and be directly exploited (e.g., fishery) or indirectly exploited (e.g., environmental protection). This use can involve either a single user or multiple users, exploiting the available natural resources. The concept of multi-use comprises a multitude of use combinations and represents an essential shift from the concept of "exclusive resource rights" to the "inclusive sharing of resources" by one or more users. These uses include individual activities from which one or more users can gain one or more benefits directly (e.g., business profit) or indirectly (protection of marine biodiversity) [34]. Another broader definition of multi-use, viewed as a key and mandatory component of MSP, was expressed by Kyvelou \& Ierapetritis [5] that conceived MU MSP as a "complex, multidimensional and context-specific process of marine management between multiple users, driven by technological, financial, socio-economic, cultural, environmental and governance related factors". This kind of MSP should be served by both planning, engineering, governance and management disciplines. Moreover, Schupp et al. [35] suggest a comprehensive categorization in four types of multi-use, following "space", "time" and "connectivity" parameters: "multi-purpose/multifunctional", "symbiotic use", "co-existence/co-location" and "subsequent/repurposing" [35]. This derives from the consideration that "multi-use" can be established, with either activities synchronously developed or when activities succeed each other. Furthermore, a distinction can be made between the multiple uses being operated by a single user or by diverse users (Table A1 in the Appendix A). This typology is mentioned here in order to support the huge potential of multi-use and its capacity to adapt in a creative way, to diverse conditions of the seas and the coastal areas.

In the framework of the EU Blue Growth strategy, the multi-use concept acquires a principal role as it seeks to achieve sustainable development of the maritime economic sectors, founding innovative enterprises and clusters [36], generating innovation and providing new jobs and ensuring, at the same time, the conservation of the marine ecosystems. Meanwhile, the Maritime Spatial Planning Directive [37] encourages the integration of the concept of multi-use in the national policies and the legislation of the EU member states which; however, is addressed in a mandatory way, only in a few cases, e.g., during the revision of the Dutch MSP approach [5].

According to the results of the above-mentioned MUSES project, the multi-uses observed in the Mediterranean are allocated firstly in tourism uses, secondly, in uses of renewable energy sources, and thirdly, in oil and natural gas extraction. Regarding tourism uses, three essential combinations were documented: a) fisheries-tourism-environmental protection; b) environmental protection-aquaculture-tourism; and c) underwater cultural heritage-tourism-environmental protection [11]. The same project indicated that maximum potential for MU development is found in tourism-driven MU arrangements (e.g., pescatourism or aquaculture/diving tourism). Pescatourism included, inter alia, in the combinations of "fisheries - tourism - environmental protection" is seen as a 
new approach towards preservation of natural resources, whilst providing supplementary income to artisanal fishermen.

\section{Results}

\subsection{Synergies between Fisheries, Fishing Tourism and MSP}

The above-mentioned place-based approach is currently the preferred path for growth in coastal areas. In this framework, the necessity to link coastal development to the broader Integrated Maritime Policy (IMP) and consequently to the particular investments involving Maritime Spatial Planning are being taken into account [26]. Fishing tourism mostly relies on FLAGs, and their strategies take into account existing MSP and Integrated Coastal Zone Management (ICZM) initiatives, as the latter often have an important tourism component. In this respect, FLAGs should initiate exchanges with the relevant MSP authorities to ensure harmonization and integration of the fishing sector's interests into the multifaceted and competitive MSP procedure that manages conflicting sea uses and creates synergies.

Several examples can be identified: in the Côte d'Azur Local Development Strategy (LDS) in France, the Fisheries Areas Network (FARNET) has established a guide on how to create benefits for the community by promoting fisheries and tourism communication and collaboration. In this guide, the significance of developing a MSP that encompasses creative and constructive interactions between these two sectors is presented. Following the guidance presented by FARNET, the local government of Côte d'Azur in the Mediterranean produced a local development strategy that allowed tourism and fisheries to interact positively and produce benefits for both industries [26]. In addition, the Scottish Government has initiated a project, supported by the European Maritime and Fisheries Fund (EMFF) to improve the quality of data of inshore fisheries around Scotland. Evidently, the data supported decision making jointly in fisheries management and in Marine Spatial Planning (MSP) [38].

We should note here that in Greece the EU MSP Directive (2014/89) was transposed into the Greek legal system with Law 4546/2018 [39]. The main responsibility for Maritime Spatial Planning at the national and regional levels lies within the competences of the Ministry of Environment and Energy. No inter-ministerial body was previewed to promote an integrated maritime policy, including fisheries, as an inherent planning priority, despite the opinions of relevant professional bodies during the consultation carried out in view of the enactment of the law [40]. In addition, no "National Spatial Strategy for the Marine Space", as previewed by the MSP law, was issued yet. The two MSP case studies carried out within the "Supporting Maritime Spatial Planning in the Eastern Mediterranean" (SUPREME) project [41] for the Inner Ionian Sea - Corinthian Gulf area, and the Myrtoon Sea/Peloponnese-Crete Passage, neither make explicit reference to MU nor to specific fishing tourism opportunities in their different planning scenarios. However, symbiotic development, only for fish farms and other uses, is mentioned in the second case study. Nevertheless, especially for the Corinthian Gulf, local NGOs, e.g., the Association for the Protection and Rational Development of the Corinthian Gulf "ARION" fully support fisheries tourism in this semi-enclosed sea. According to them, fishing tourism in Greece is a powerful rural product-the best available on the European market today-and probably one of the best in the world, and can have multiple benefits. Benefits include attracting more tourists, promoting other rural products along with fishing tourism, keeping young people in the fishing profession, discussing problems of fisheries-not only at a national level, but mainly at a European level—and familiarizing fishermen with the European fisheries institutions, to which they should participate, limiting the fishing effort that has negative impact to the already reduced fish stocks and enhancing fishermen's income. 


\subsection{The Greek Case Study}

\subsubsection{Situation and Potentials of the Greek Fishing Industry}

Throughout the thirty-year period 1980-2011, according to the data provided by F.A.O [42], the per capita production of Greek fisheries and other products was larger than the respective production worldwide (Figure A1 in the Appendix A). It should be noted that the per capita production of fishery and other products in 1997 reached 25 tonnes per year, while the respective average production worldwide was a little more than 15 tonnes per year. The reduction observed in the last fifteen years resulted in a first time marginally lower level of the per capita production of fishery products compared to the global level in the two-year period 2012-2013 [43]. In absolute figures and distinguishing between the national production in deep-sea fishery products and aquaculture products, in 2017 it amounted to 203,612 tonnes in total, $38.4 \%$ (78,190 tonnes) of which were deep-sea products, and the remaining $61.6 \%(125,422$ tonnes) were aquaculture products. In the last years, the fishing and aquaculture sectors contribute stably by $0.4 \%$ to the national GDP, presenting higher ratings than the total of the EU member states or than Turkey, which presents a remarkable activity in these sectors [44]. The respective gross value added was 645 million euros in 2016, presenting a reduction of 60 million euros compared to 2008, i.e., the starting year of the economic and financial crisis.

According to recent available data, Greece produces 170,000 tonnes, 106,000 of which come from aquaculture business activities and 64,000 tonnes from artisanal fisheries activities (Figure A2 in the Appendix A) forming in total $2.6 \%$ of the total fishery production in the EU and $0.1 \%$ of the global production. Greece is amongst the five (5) EU member states that produce in total three quarters of the total aquaculture production, both in quantity and in value. More specifically, in terms of economic value, Greece ranks fourth (11\%) after the United Kingdom (24\%), France (15\%), Spain (12\%) and Italy (11\%) [45].

In regards to the Greek fishing fleet, according to the recent report of the Directorate General for Fisheries of the Ministry of Rural Development and Food, it consists of 14,985 vessels with a total capacity of 71,085 gigatonnes (GT) and a total power of $426,683 \mathrm{kw}$. The average age of the vessels is 30.22 years, presenting an increase in relation to the corresponding median age of the previous year (2016) in the order of 2.7\% [45]. It is worth noting that the contribution of small vessels of $0-11 \mathrm{~m}$ length to the Greek fleet is $94.3 \%$, followed by vessels of $12-23 \mathrm{~m}$ long, amounting to $4.6 \%$, and vessels of 24-39 m long, amounting to just $1.1 \%$.

In terms of employment, according to recent available data (2015), the fishery sector, employs in total a full-time equivalent (FTE) of 23,431 people, the greatest percentage of which is found in vessels of $0-11 \mathrm{~m}$ length, $15 \%$ in vessels of $12-23 \mathrm{~m}$ length and the remaining $6 \%$ in vessels of $24-39 \mathrm{~m}$ length. Regarding the standard gear of the Greek fishing fleet, $67 \%$ is equipped with gill nets and entangling nets and $25 \%$ with hooks and lines (the remaining $8 \%$ has other equipment) [45] (Figure A3 in the Appendix A).

Looking at gender, the workforce employed in Greek fisheries is composed almost as a whole by men ( $96 \%$ men and $4 \%$ from women in total a full-time equivalent) and is rather aging. Moreover, $74.8 \%$ of the employees are at the age of over 40 years, analyzed to $64.4 \%$ between $40-64$ years and $10.4 \%$ over the age of 65 years. In particular, in small-scale fisheries, workers over 40 years are $79.3 \%$, analyzed at $67.3 \%$ between $40-64$ years of age and $12 \%$ over 65 years. The labor force for small-scale fisheries, based on the level of education, is classified as a municipal-high school graduates who make up $57 \%$ of high school graduates $36.5 \%$ and higher education graduates $6.2 \%$ [46].

The major problems faced by coastal fishermen, according to a survey conducted by the Greek Ministry of Rural development and Food [46], emerge in excess of the damage to fishing gears by mammals ( $82 \%$ positive response), the reduction of catches due to overfishing ( $62 \%$ positive response), competition with amateur and retired fishermen ( $62 \%$ positive response), the reduced catch value $(60 \%)$ and reduced consumer purchasing power ( $51 \%$ positive response), all being factors that increasingly 
shrink fishing income and push Greek fishermen to seek an opportunity to acquire supplementary income [46].

Nevertheless, fisheries remain an activity of fundamental prominence for the coastal/island communities of Greece for many centuries. As shown by archeozoological research the fish species caught in the Aegean archipelago are basically identical for about 100 centuries [47]. However, the industry suffers from over-exploitation of marine resources, destructive fishing practices and illegal techniques, overfishing, habitat destruction, pollution and climate change impacts. Consequently, the fishing industry runs the risk of collapse with major socio-economic and environmental costs for island and coastal communities that are, especially in small islands, strongly dependent to this activity. There is urgency since the rhythm of decline of fish stocks is accelerating. For instance, research in the eastern Aegean Sea has indicated a shrink of up to $50 \%$ in catch levels of small-scale fisheries between 2009 and 2011 [47]. As a consequence of decades of unsustainable national and EU fishing policies, fishermen are technically improving their vessels and equipment, using largely improved catching methods, and covering larger fishing areas. Nevertheless, despite this increased effort, small-scale fishery catches levels continue to decline.

Small-scale fisheries occupy $97 \%$ of the Greek fishing vessels [46], and provide $50 \%$ of the total national catch, using nets and other traditional techniques. They are essential component of the coastal and island economy, society and culture, in other words of the coastal/island landscape viewed as a social-ecological system [48].

\subsubsection{Fisheries and Tourism Co-Existence on the Study Area (Greece)}

Greek coastal and island communities have a long and very particular fishing tradition. Besides, there is a remarkable fishery activity observed in the last thirty years, as pronounced in the above section, and a tourism orientation of the coastal communities and the national economy as a whole. All of the above make fishing tourism an activity whose potential needs to be explored and further exploited.

The view of Greek legislation [49] about fishing tourism is quite broad and integrated: it defines fishing tourism as a form of rural tourism that involves the provision of services pertaining to fishery, sponge fishing, aquaculture and the relative practices and techniques to visitors-tourists, who combine their vacation with fishery activities provided offshore, in order to entertain through fishery, hands-on experience, acquaintance with local traditions, local customs and local cuisine, the spreading of fishery culture and the economic stimulus of the social fabric at a local level.

Moreover, the relevant European funds (EMFF) for the programming period 2014-2020 provide the ability for pilot implementation of multi-use in tourism and fishery activities. Specifically, the Greek Operational Programme for "Fisheries and Sea 2014-2020" implements an integrated policy related to fisheries and aquaculture, in order to enhance the social and economic prosperity primarily of island and coastal areas, based on an endogenous "bottom up" and co-management approach involving the participation of public and private sector bodies. Through priority 4 "Increase of employment and territorial cohesion", the programme provides approximately 54 million euros $(10.4 \%$ of the total programme budget) to Community-Led Local Development Programmes on Fisheries (C.L.L.D). These target specific sub-regional areas (with a population of at least 10,000-15,000 inhabitants) highly dependent on fishery activities and facing socio-economic difficulties and severe lack of infrastructures, while possessing natural assets able to enhance their attractiveness as tourist destinations.

Therefore, a favourable framework is being formed through maximizing the participation of fisheries and aquaculture, to reverse negative developments and achieve sustainable development of the coastal areas. The ultimate goal of these initiatives is to preserve/create jobs, exploit the fisheries and aquaculture products and the possibilities offered by the sea in general, promote the quality of the coastal environment, as well as support the diversification or economic and social contexts in areas facing socio-economic struggles, due to changes in the fisheries sector. It is rather apparent that the "multi-use" is fully supported by the strategy, since main strategic goal is the "... enhancement of sustainable development in the selected fisheries and aquaculture areas that will be supported by the creation 
of a multiple employment and interconnection standard of the production sectors among them in these areas". Besides, general objectives highlight the competitiveness of fishery and aquaculture areas, through reforming and reorienting their production base and creating new jobs, beyond the fishing sector, while the specific objectives target the increase of value added of fishery products, the promotion of ecotourism, the maintenance and creation of new jobs and the promotion of the quality of the coastal environment.

However, there are a lot of obstacles to the development of fishing tourism in the local market such as the inherent weaknesses of the Greek local rural entrepreneurship, i.e., the limited access to funding resources and the lack of tax incentives. As for the social and economic structure, fishing tourism in Greek coastal areas may be poor in terms of other business start-up resources, such as public and civic assistance and entrepreneurial culture, slower growth of technology and infrastructure, lower absorption rate of technological developments and limited connections to the outside world [50-52]. Another obstacle to the Greek fishing tourism may be the ageing and the low educational level of fishers in combination with their incapability in designing and implementing particular tourism services and appropriate marketing strategies, although young fishers are more competent and often educated in these issues.

Furthermore, there is an inertia in making the shift from the non-competitive "sea, sand and sun" model to other forms of touristic offer and the problem of seasonality is still very present. It is also the ageing of the fishing vessels and the strict legal requirements [53] for technical adjustments related to tourists transport along with the consequent need for funding resources that pose important obstacles to the development of fishing tourism. Naturally, the profitability is substantially limited due to the high operational costs, often rendering unprofitable and uncertain, the engagement in activity. To note that fishing trips may last 9-10 hours, during which, the fishermen must present and explain the fishery activities, actually fish, and often prepare lunch for the passengers on board.

In addition, the current institutional framework [53] previews rules for a safe tourist navigation and a safe participation of tourists in the fishing effort, as the granting of a fishing tourism license to professional fishermen requires that the vessel holds a Certificate of Airworthiness and the activity runs in compliance with the relevant safety rules, for staffing, hygiene and suitability to boarding passengers. At the same time, a necessary precondition for the granting of the relevant license, in accordance with the current institutional framework, is the existence of a special space on board ensuring safety of tourists during their fishing activities, the use of specific manual fishing gears and a guarantee provided by the commander that the intended tourist activity relates only to operations where the safety of the participating tourists is not at risk.

However, the safety regulations applicable to this activity vary considerably between member states, and solutions should be found to the exploitation of existing fishing fleets, in particular small-scale fishing vessels, without excessive costs and, at the same time, without endangering safety. As the European Parliament has suggested [54] safety regulations should be harmonized and facilitated by access to and use of funding through available financial instruments such as the European Maritime and Fisheries Fund (EMFF).

Finally, we should not forget that the small-scale of the activity is advantage and disadvantage at the same time. The soft and fleeting character of the activity due to the lack of heavy infrastructure and the minimum number of tourists limits the impacts on the environment but hampers its viability. This is compromised by the small size of the fishing vessels $(94.3 \%$ of the vessels has a length of $0-11 \mathrm{~m})$ that combined with strict fishing tourism specifications (e.g. kitchen space and equipment) limits the number of passengers to 7-10 people. There is consequently a de facto competition by large tourism enterprises that organize sea excursions and are able to accommodate greater numbers of passengers in their larger vessels, achieving lower transportation costs and, thus, higher profits [55]. 


\subsubsection{FLAGs and Fishing Tourism in Greece}

Following Axis 4 of the European Fisheries Fund (EFF) entitled "Sustainable development of fisheries areas" local fisheries areas presenting sufficient coherence in geographical, economic and social terms were selected in Greece and local co-management partnerships entitled "Fisheries Local Action Groups" (FLAGs) involving fisheries actors and other local private and public stakeholders, were created. The aim was the development of partnerships involving the wider community and the design and implementation of a local development strategy for the areas. These are endogenous local development strategies that are inextricably linked to the characteristics and needs of the fishing areas. A crucial role in a place-based, bottom-up development approach plays the establishment of a "sense of place" which is based on common characteristics, problems or simply features that give inhabitants from the fisheries area distinct local identity. This makes part of the social capital of the area, a kind of widespread trust within the local community, motivating local actors to provide their own funds, time and effort, making cooperation easier, promoting knowledge diffusion and enhancing innovation [56]. In this context, for the period 2014-2020, thirty-three FLAGs were established in Greece giving to the country a leading role together with Italy in the Mediterranean (Table 1 below). As a result, 31 FLAG strategies were selected and are being implemented by multi-funded groups, managing LEADER as well as fisheries CLLD (Community-Led Local Development). Kavala and Iraklion FLAGs implement a purely EMFF funded strategy. What is remarkable is that seventeen FLAGs strategies that is almost $50 \%$ of the whole, have set fishing tourism as one of their key thematic directions (see Figure 1 below and Table A2 in the Appendix A).

Table 1. Fisheries Local Action Groups in the European Union (EU) member states of the Eastern Mediterranean, 2017.

\begin{tabular}{ccc}
\hline Country & FLAGs & $\begin{array}{c}\text { Mediterranean FLAG's for } \\
\text { Fishing Tourism }\end{array}$ \\
\hline Italy & 35 & 23 \\
\hline Croatia & 7 & 6 \\
\hline Cyprus & 3 & - \\
\hline Slovenia & 4 & 1 \\
\hline Greece & 33 & 17 \\
\hline Total & $\mathbf{8 2}$ & $\mathbf{4 7}$
\end{tabular}

Source: FAO. The State of Mediterranean and Black Sea Fisheries; General Fisheries Commission for the Mediterranean: Rome, Italy, 2016 [16].and own elaboration by authors.

According to the most recently available data of the Greek Ministry of Rural Development and Food (Directorate of Fishing Activity and Product Control), the nationwide number of fishermen that are officially engaged in fishing tourism activities is rather limited and accounts for 155 active licenses. The fishing tourism enterprises officially operating per region (nomenclature of territorial units for statistics, NUTS 2) and regional unit (NUTS 3) in late 2019 are visualized in Table A1 in the Appendix A.

The largest number is concentrated in the region of South Aegean (32.3\% of the total) distributed in the big islands of Rhodes, Syros and Naxos. Followed by the Region of Crete (14.2\% of the total) and the Attica region (10.3\% to the total). In the fourth and fifth positions are the regions of Thessaly, which makes up 7.7\% and East Macedonia and Thrace, with 7.1\% (see Table A3 in the Appendix A). Figure 2 below summarizes the fishing tourism intensity at regional unit level (NUTS 3) and clearly demonstrates that the most active regional units on fishing tourism entrepreneurial initiatives are the ones of Rhodes (24 fishermen) and Attica (16 fishermen). 


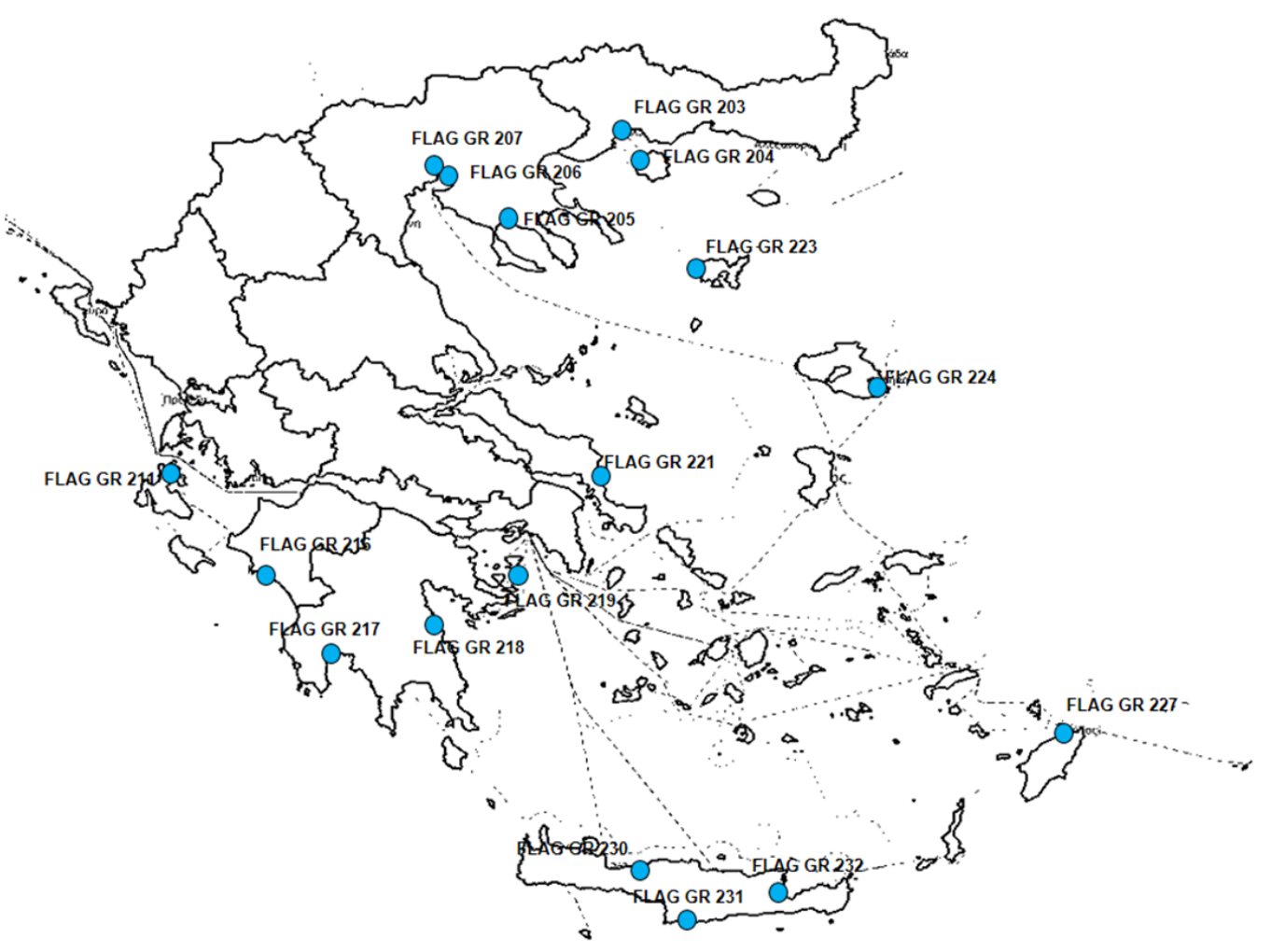

Figure 1. Distribution of Fisheries Local Action Groups (FLAGs) for fishing tourism in Greece, 2017. Source of data: FARNET. Greece, Country Factsheet [33], and own elaboration by authors.

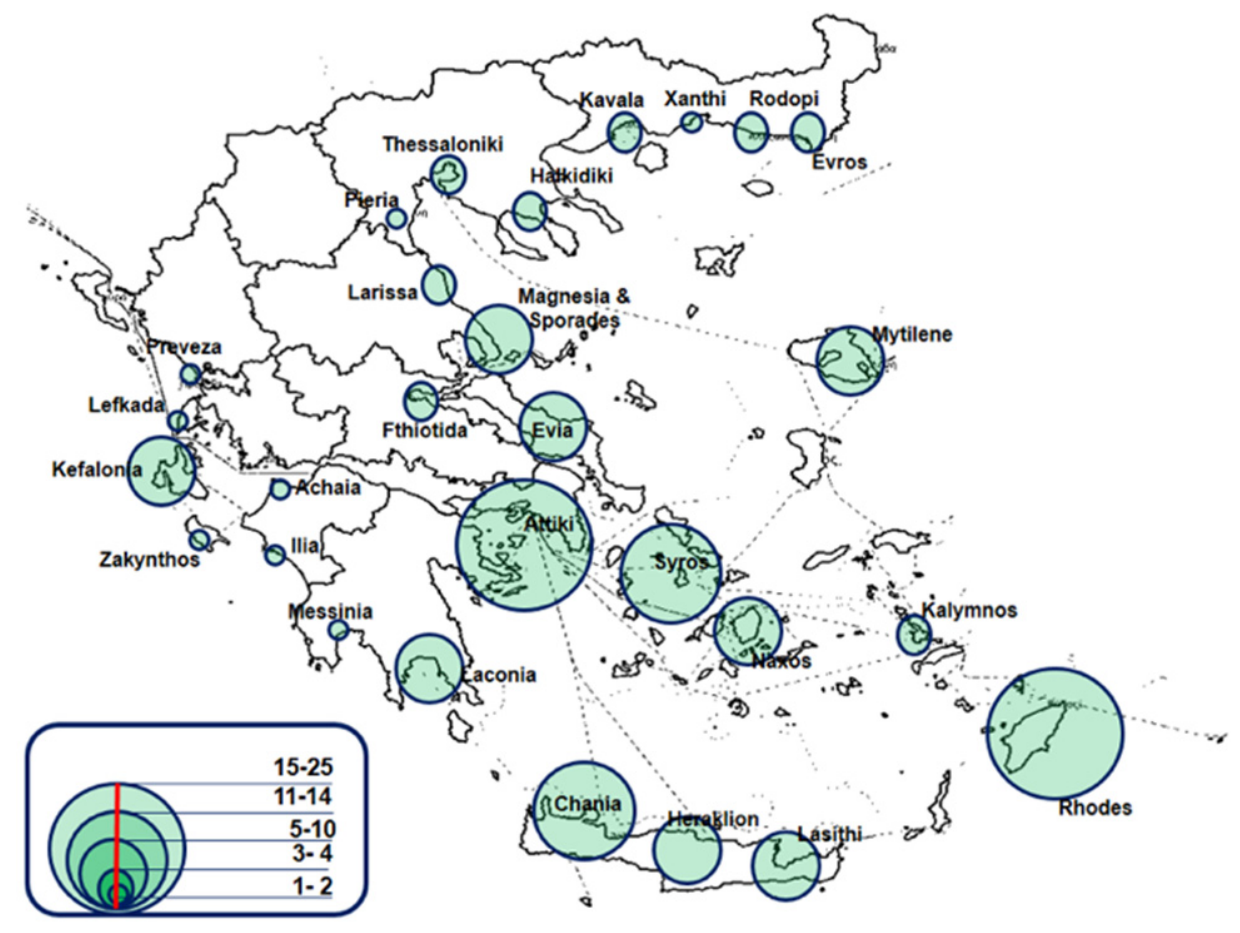

Figure 2. Fishing tourism intensity in Greece at Regional Unit level (nomenclature of territorial units for statistics, NUTS 3), 2019. Data Source: Ministry of Rural Development and Food, Directorate of Fishing Activity and Product Control, 2019, and own elaboration by authors. 
Apparently, through all of the above initiatives, fishing tourism, having considerably grown over the last two decades in Italy, is now gaining ground in other Mediterranean locations as well. It is certainly an interesting fishing tourism assemblage providing visitors the opportunity to obtain knowledge about a deeply community-rooted economic, social and cultural endeavour at risk of extermination, whilst decreasing environmental impacts and supporting the maintenance of a traditional employment.

\subsubsection{Perceptions of Fisheries Tourism Co-Existence by Different Stakeholders}

As mentioned in the "Materials and Methods" section, in order to confirm our hypotheses on the role of fishing tourism, both in marine spatial planning and local development in Greece, a survey was carried out based on structured interviews to different stakeholders (state services responsible for fisheries, regional authorities mainly from Attica and Rhodes that have the greater number of FLAGs, Marine Research Institutes, certain FLAGs spread all over the country, local fishers mainly in the Cyclades islands and their associations, environmental NGOs, individual experts). The most representative target groups were a: the fishing enterprises and the associations of local fishermen $(15,1 \%$ of the sample); $b$ : the co-management schemes (33,4\%) comprising Development Companies $(15.2 \%)$ and FLAGs $(18,2 \%)$; c: the independent experts, academia and the Marine Research Institutions $(21,2 \%)$ and $d$ : the environmental NGOs $(6 \%)$, mainly WWF, which is extremely proactive in promoting fisheries diversification policies and mechanics [56].

The purpose was to detect their multiple perceptions for both the potentials and the many challenges that fisheries-tourism combination is actually facing and probably identify solutions for further development of the activity in the country. The results of this brief survey are summarized in the following Table 2 grouped in four major thematic units: "Biology-Ecology", "Socio-economics, Culture and local development", "Economic viability, operation, innovation, and marketing" and finally "Governance, MSP, legal framework and Funding". These key themes were suggested by the authors when structuring their survey to make it more understandable to the respondents, distinguishing the different environments in which the activity takes place (bio-physical, socio-cultural, economic and financial, operational and governance related) and were discussed and verified with key stakeholders. Besides this survey, local visits were realized and face-to-face contacts with local fishers and tourism entrepreneurs (especially in the Small Cyclades islands) have taken place to detect and verify the status of fisheries, their familiarization with the idea of fishing tourism, as well as their perception about further development of such an activity in their fishing communities (Figure A4 in the Appendix A). 
Table 2. Advantages and disadvantages of co-existence of artisanal fisheries and tourism, as perceived by stakeholders. Source: structured interview-based survey, designed by authors and addressed to key actors and stakeholders.

\section{Key Themes}

Potentials/Advantages

Decompressing already reduced fish stock

Reduction of artisanal fisheries effort to tackle overfishing.

Theme 1: Biology/ecology/ecosystem-based management.

- Environmental education/awareness raising related to fishing and tourism within or near marine protected areas (MPAs).

- Expand employment and territorial cohesion in coastal and island communities depending on fishing activity.

- Diversifying traditional fishing activities and boosting fishermen's' income.

- Familiarizing fishermen and their families with the internet and the relevant e-services (fishing tourism platforms etc.).

Theme 2: Socio-economics, culture, local development.

Keeping young people in the fishing profession.

- Attraction of visitors seeking authentic experiences- development of niche markets.

- Fishers can play a central role in the preservation of the cultural identity of their territories.

- Touristic assets of fishing villages providing diversification opportunities.
Challenges/Disadvantages

- Low attractiveness as far as

Vegetarianism/Veganism and other similar group are concerned.

- Pollution/Marine litter due to touristic pressure.

- Risk of non-compensation of fishermen for lost fishing opportunities.

- Increased taxes to the touristic activity making the combination of fisheries and tourism unsustainable.

- Possible increased competition from other professional groups (e.g., other tourism operators)

- Competition and conflicts between local fishermen operating in the same sea area.

- Absence of Schools of Fisheries and of traditional shipbuilders.

- Absence of business start-up resources in coastal/small island areas such as public and civic assistance.

- Lack of entrepreneurial culture.

- Ageing and low educational level of human resources in combination with lack of specialization of human resources may cause law level of touristic satisfaction.
Theme 3:

Economic viability, operation and innovation, marketing
- Integrating innovation in fishing activity. Retail infrastructure in port areas, in fishing shelters in tourist areas (according to the existing framework) such as in Varkiza or in Mykonos.

- Promotion of well-known local agricultural products.

- Fishing areas can promote cooperative marketin campaigns with other tourist destinations in the region- alliance can generate mutual profits.
- The short period of the activity.

- The ageing of the Greek vessels.

- EU and national compensations to fishermen to destroy their vessels and abolish their fishing licenses.

- Traditional boats are taxed the same as modern and faster boats of equal size.

- High costs of investment to adapt vessels to tourism related function (requirement for technical adjustments to professional fishing vessels, due to their touristic activity). 
Table 2. Cont

\begin{tabular}{|c|c|c|}
\hline Key Themes & Potentials/Advantages & Challenges/Disadvantages \\
\hline $\begin{array}{l}\text { Theme 4: } \\
\text { Governance, MSP, legal framework, taxation, funding. }\end{array}$ & $\begin{array}{l}\text { - Organizing events on the country's fishing } \\
\text { tradition (e.g., fishing tradition days). } \\
\text { Fishers can profit from EU and specific funding } \\
\text { directed to cultural fisheries, incl. tourism-driven } \\
\text { projects under the European Maritime and } \\
\text { Fisheries Fund (EMFF). } \\
\text { Potential to create the triplet of } \\
\text { fisheries-tourism-environmental protection in or } \\
\text { near MPAs. } \\
\text { - Potential for awareness raising of tourists about } \\
\text { fishing related environmental problems } \\
\text { threatening the seas e.g., ghost fishing. } \\
\text { State financial support to further diversify } \\
\text { fishermen's profession and achieve temporary } \\
\text { cessation-reduction in fishing effort. } \\
\text { Reform of existing legislation in order to enable } \\
\text { fishermen to broaden their touristic activity } \\
\text { beyond the embarking of tourists on small-scale } \\
\text { fishing boats for recreational and } \\
\text { cultural purposes. } \\
\text { Involvement of fishers in planning and } \\
\text { decision-making processes concerning coastal and } \\
\text { marine areas. } \\
\text { Familiarizing fishermen with the European } \\
\text { fisheries institutions. }\end{array}$ & $\begin{array}{l}\text { - Lack of Fishing Tourism Associations, lack of } \\
\text { training and certification scheme. } \\
\text { Fisheries-tourism co-existence may cause further } \\
\text { delays in the physical and economic integration of } \\
\text { C.L.L.D. Programmes on fisheries for the } \\
\text { 2014-2020 period. } \\
\text { Lack of provision by law to enable the activity } \\
\text { (fishing tourism) in inland waters of communities } \\
\text { that have as main source of income the } \\
\text { river fishing. } \\
\text { Extreme pressure from the competent authorities } \\
\text { to comply with the rules, although not } \\
\text { accompanied by the necessary support for lifelong } \\
\text { learning, training etc. } \\
\text { Bureaucracy. } \\
\text { Despite the existing Joint Ministerial decision for } \\
\text { fishing tourism, the Ministry of Tourism law } \\
\text { (issued in 2019) does not allocate exclusiveness of } \\
\text { fishing tourism activity to coastal fishermen, } \\
\text { leaving room for thousands of yacht owners who } \\
\text { advertise fishing tourism online without fishing } \\
\text { experience at sea and not having the proper } \\
\text { knowledge. This is a huge problem for local } \\
\text { fishermen since their small-scale vessels cannot } \\
\text { compete the modern and luxurious yachts, thus } \\
\text { suffering from unfair competition. } \\
\text { Risk for fishermen of losing their fishing license if } \\
\text { their income from non-fishing activities becomes } \\
\text { higher than the one from fishing. }\end{array}$ \\
\hline
\end{tabular}


As for the question concerning how it can be possible to further develop the fishing tourism in the country, apart from the references to the need of information, training, tax incentives and marketing, the respondents focused on the collaboration between the fishing associations and the tourism companies responsible for designing the appropriate products with the involvement of the state and the regional authorities. They also stressed the need to organize information and awareness-raising campaigns, addressing both to the fishermen and to the consumers.

In their great majority, they opted for a complete and comprehensive information to the consumers about their possible choices to encourage responsible consumer behavior and support the fisheries industry sustainability. The establishment of a monitoring and evaluation system was judged necessary, since the evaluation process will probably determine new strategies and priorities, taking into account factors such as marine spatial planning, new uses of the marine space, conflict management between marine and coastal tourism, institutional regimes, etc. It was also stated by experts that there is a significant spatio-temporal variation of the fishery and tourism products and this is a challenge to be tackled through an opportunity evaluation and a cost-benefit analysis.

Nevertheless, an encouraging result is that through the survey process, fishers and NGOs seem to be substantially influenced by SDG14b, which is appealing for providing access of fishers to resources and markets. Fishers seem quite convinced that the opening of the traditional fishing activity to other marine activities and related markets is a sine-qua-non condition for maintaining their livelihood. One of their main concerns is the fact that taxes to the touristic activity are unaffordable; thus, making the combination of fisheries and tourism unsustainable for the time being.

\section{Discussion}

With over $65 \%$ of the fish stocks in the Mediterranean being below the critical biological limits and catch levels having deteriorated by $30 \%$ during the last 10 years, the Mediterranean fisheries industry is seriously threatened.

Especially, small-scale fisheries, being the key focus of this article, have a long tradition in Greece, and together with aquaculture they present higher rates than in the total of the EU member states, steadily contributing by $0.4 \%$ to the national GDP. The per capita production of Greek fishery and other products is superior to the corresponding production worldwide. However, the industry faces severe challenges like overfishing in combination with competition by amateur and retired fishermen, reduced catches value and loss of consumer purchasing power, due mainly to the economic crisis and the austerity measures imposed. All these factors are increasingly shrinking fishing income and pushing Greek fishermen to seek opportunities of diversifying their activity and discover new income sources but also provoking competition and conflicts between fishermen operating in the same sea area.

In this context, the authors believe that efficient options for fisheries diversification can only happen when positive and symbiotic forms of coordination of fisheries with other maritime activities take place. Here comes the contribution of the concept and practice of multi-use (MU) which is defined as the co-existence of maritime uses in close geographic proximity, seeking to achieve sustainable development of the maritime economic sectors. Since the EU Blue Growth strategy gives a central role to this concept and the MSP Directive encourages the integration of multi-use of different scales in national policies and legislation of the EU member states, tourism-driven MU-related entrepreneurship can be fully supported in the Mediterranean basin.

In Greece, the national tourism strategy promotes alternative types of thematic tourism and fishing tourism can be easily developed as an alternative to massive coastal tourism, providing personalized services to different age groups and authentic experience to tourists. As an example, silver tourism or cultural tourism can be successful alternatives since the aging of the world population entails an emergent market with higher available income and free time for traveling [32] and cultural tourism is recognized as a major element of global tourism consumption, representing over $39 \%$ of tourism arrivals [57]. Therefore, co-existence of fishing and tourism presents a positive perspective as a soft maritime activity in Greek coastal and island communities. This is due to the small size of the main 
infrastructure that is the Greek fishing vessels (Figure A3 in the Appendix A) that are, despite all, developing a remarkable fishery activity, around which a solid and diverse inherent fishing tradition is articulated.

Moreover, the presence of a series of marine protected areas (MPAs) in the Greek territorial waters and the emerging trend of multi-use practices in the marine space, also provides opportunities for diversified fishing tourism activities, fostering initiatives involving environmental education and awareness raising, and strong correlation between fishery, tourism, and environmental protection (and also, although to a lesser degree, underwater or maritime cultural heritage) [58]. In 2018, the country increased the designation of its Natura 2000 marine space from $6.12 \%$ to $22 \%$; thus, contributing to the attainment of the global targets on protected areas [59] and during the last year the designation of managing authorities is under process and the relevant legal framework under revision and improvement. Although this seems to be a turning point in marine conservation in the country, the achievement of the dual socioeconomic and ecological mandate of sustainable development remains a major challenge in which multi-use, especially fishing tourism, can have a catalytic role. Fishing tourism as a form of alternative tourism attracting visitors seeking genuine and authentic experiences can certainly serve conservation targets.

The activity, enriching the locally offered tourism product can be interconnected with other local tourist activities, developing new activities and offering recreational and educational satisfactions and services to tourists with multiplier effects. Moreover, it can enhance local identities, social status of the fishermen themselves and give them a role as important stakeholders in MSP procedures, including those that are related to land-sea interaction. The existence of many Fisheries Local Action Groups all over the country (Figure 2) is also a positive sign, even if exploitation of the funding opportunities remains in a premature phase.

Despite these potentials, there are many challenges and barriers that can hamper the development of fishing tourism. Among the difficulties already described or evoked by stakeholders most important are the ageing of the vessels (the average age was 30.22 years in 2017), the ageing and the low educational level and skills of the fishermen and the crew, the inherent weaknesses of the Greek local entrepreneurship in the peripheral regions due to the limited access to funding resources and the tax burdens. Complete lack of tax incentives for fishing tourism entrepreneurship is also observed along with penury of business start-up resources. The future will certainly depend on the ability of local businessmen to efficiently cope with seasonality and adapt to more advanced tourism models. The limited passengers related capacity (7-10 people) imposed by the legal fishing tourism specifications [44] due to the small size of the fishing vessels (Figure A5 in the Appendix A) should be reversed in advantage, marketizing the whole as a soft, fleeting, less polluting activity providing knowledge and satisfactions and approaching tourist to nature and culture of places.

Consequently, even if the future of fishing tourism in Greece is away from being fully guaranteed, it presents positive perspectives. Of course, several measures should be taken by the European Commission, the State and the regional and local authorities to create favorable conditions for the development of the industry after listening and dialoguing with fishermen on their real problems and needs through the already established co-management schemes.

\section{Conclusions}

The aim of the current article was to provide insights on the Eastern Mediterranean artisanal fisheries inadequately studied and poorly integrated to local development strategies so far and more specifically to explore diversification options for their sustainability. A key conclusion is that, despite the many challenges and barriers, either objective or as perceived by different key actors and stakeholders, the fishing tourism activity is a powerful option, particularly if a strong correlation and assemblage is favoured between artisanal fisheries, tourism, environmental protection and to a lesser degree underwater cultural heritage, involving Marine Protected Areas and UCH/MCH sites. This can be a small-scale but unique pattern for a "win-win-win" multi-use in the Eastern Mediterranean Sea-basin. 
It can ensure multiple benefits—economic, environmental, social and cultural—for the coastal and island communities; thus, boosting sustainable local development and employment opportunities and favoring a balanced and cohesive multi-use MSP. In this way, a series of Sustainable Development Goals (SDGs) may be fulfilled, especially SDG1 concerning food security, SDG2 about poverty alleviation and SDG3 about community wellbeing focusing on small island areas in the country that suffer from high living costs [60] and limited employment opportunities to ensure their livelihood, and SDG8 about economic growth, with emphasis in the Greek insular and micro-insular space where key question is to what extent blue growth potential can create inclusive prosperity $[60,61]$.

The example of Greek coastal/island areas is extremely relevant for exploring further options of such a promising maritime planning and co-management scheme, presenting multiple benefits for the coastal and island communities.

The analysis, including stakeholders' insights and experts' observations, identified some key limitations: First of all, there is a significant spatio-temporal variation of the fishery and tourism products, so there is a need for a relevant opportunity evaluation and cost-benefit analyses. On the other hand, multi-use should be duly framed and fully promoted by the National Strategy for the marine space (previewed by the above-mentioned law 4546/2018), which is actually under elaboration and constitutes a key policy document for the future of MSP in Greece. Furthermore, efficient coordination between sectorial policies (tourism, fisheries) and between public (e.g., local and regional authorities) and private sectors (e.g., international tourism agencies to provide fishing tourism with clients from all over the world) is needed. Despite this, the general outcome is that fishing tourism is a soft and sustainable option for artisanal fisheries diversification, mostly contributing to the survival of artisanal fisheries which enhances place attachment and contributes to the preservation of local identity and intangible heritage of the fishing communities. This is particularly interesting from a local development policy point of view, since the Mediterranean local and island communities are economically dependent on fisheries [62] while intrinsically associated to the coastal and marine ecosystems in the sense of co-evolving as an integral social-ecological system.

As Schindler said "There's inherent value in the identity of being a fishing community. That sense of community identity is basically reinforced by the fact that the community is adapting to the ecosystem, which is always changing". In this sense, fishing tourism may substantially contribute to the reconnection of nature and culture, towards quality marine and coastal landscapes [63] as the latter were defined by the European Landscape Convention.

Author Contributions: Conceptualization, S.S.I.K. and D.G.I.; methodology, S.S.I.K. and D.G.I.; validation, S.S.I.K. and D.G.I.; formal analysis, S.S.I.K. and D.G.I.; investigation, S.S.I.K. and D.G.I.; resources, S.S.I.K. and D.G.I.; data curation, S.S.I.K. and D.G.I.; writing-original draft preparation, S.S.I.K. and D.G.I.; writing-review and editing, S.S.I.K.; visualization, S.S.I.K. and D.G.I.; supervision, S.S.I.K.; project administration, S.S.I.K. and D.G.I. All authors have read and agreed to the published version of the manuscript.

Funding: This research received no external funding.

Acknowledgments: The authors would like to warmly thank Ms. Maria Tsouvala, President of the Panhellenic Association of Public Sector Ichthyologists for her precious contributions and constructive comments on their research. They also express their gratitude to all the stakeholders and experts involved in the co-development process through the designed survey about fishing tourism as marine multi-use setting in Greece. Besides, the authors would like to warmly thank the three anonymous reviewers for their substantial contribution to the improvement of their manuscript.

Conflicts of Interest: The authors declare no conflict of interest. 


\section{Appendix A}

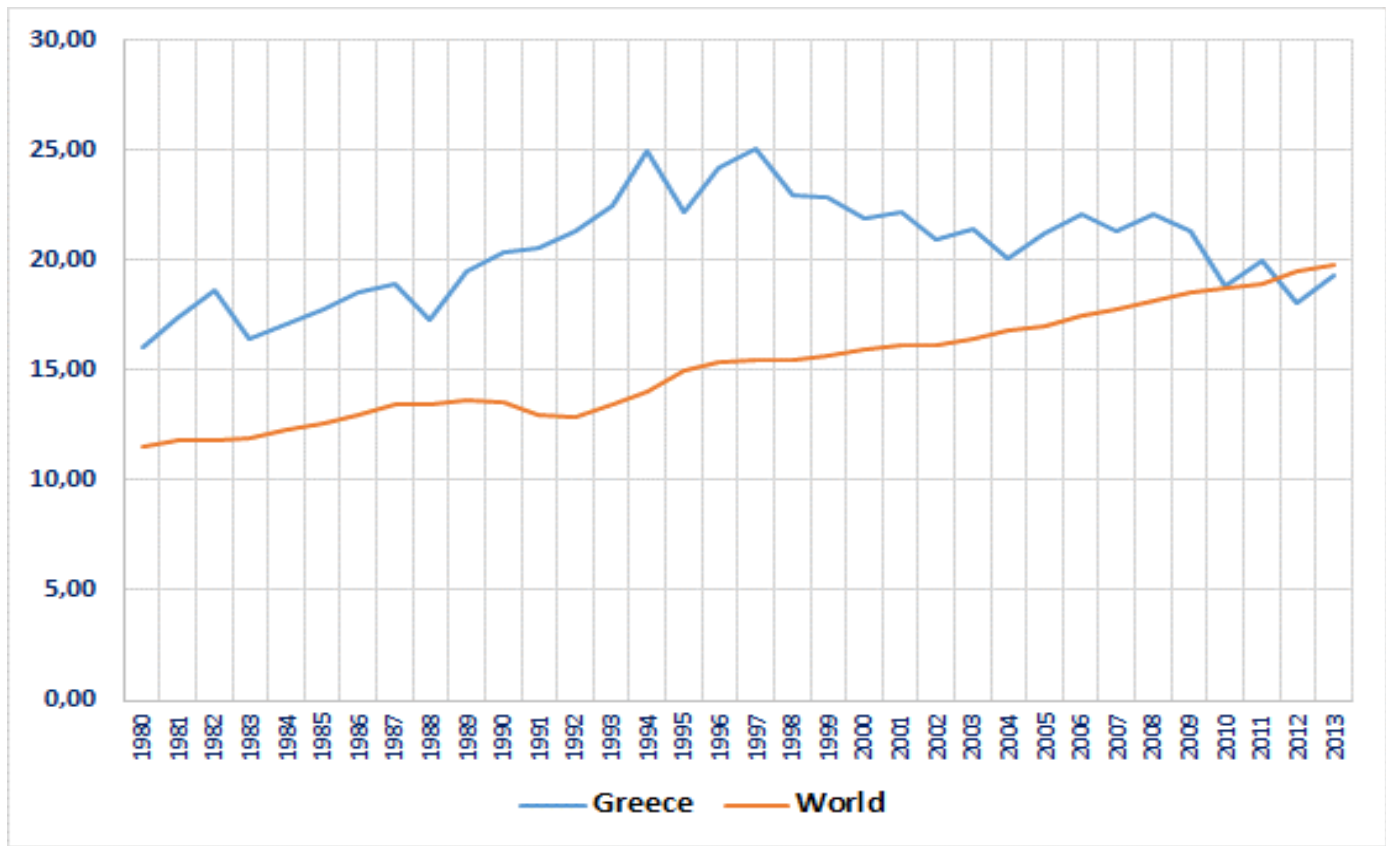

Figure A1. Per capita offer of fishery and other products in Greece and worldwide (in tonnes). Data Source: FARNET Guide n 8: Marketing the local catch. European Commission, Directorate-General for Maritime Affairs and Fisheries, Director-General, 2014 and visualization by authors.

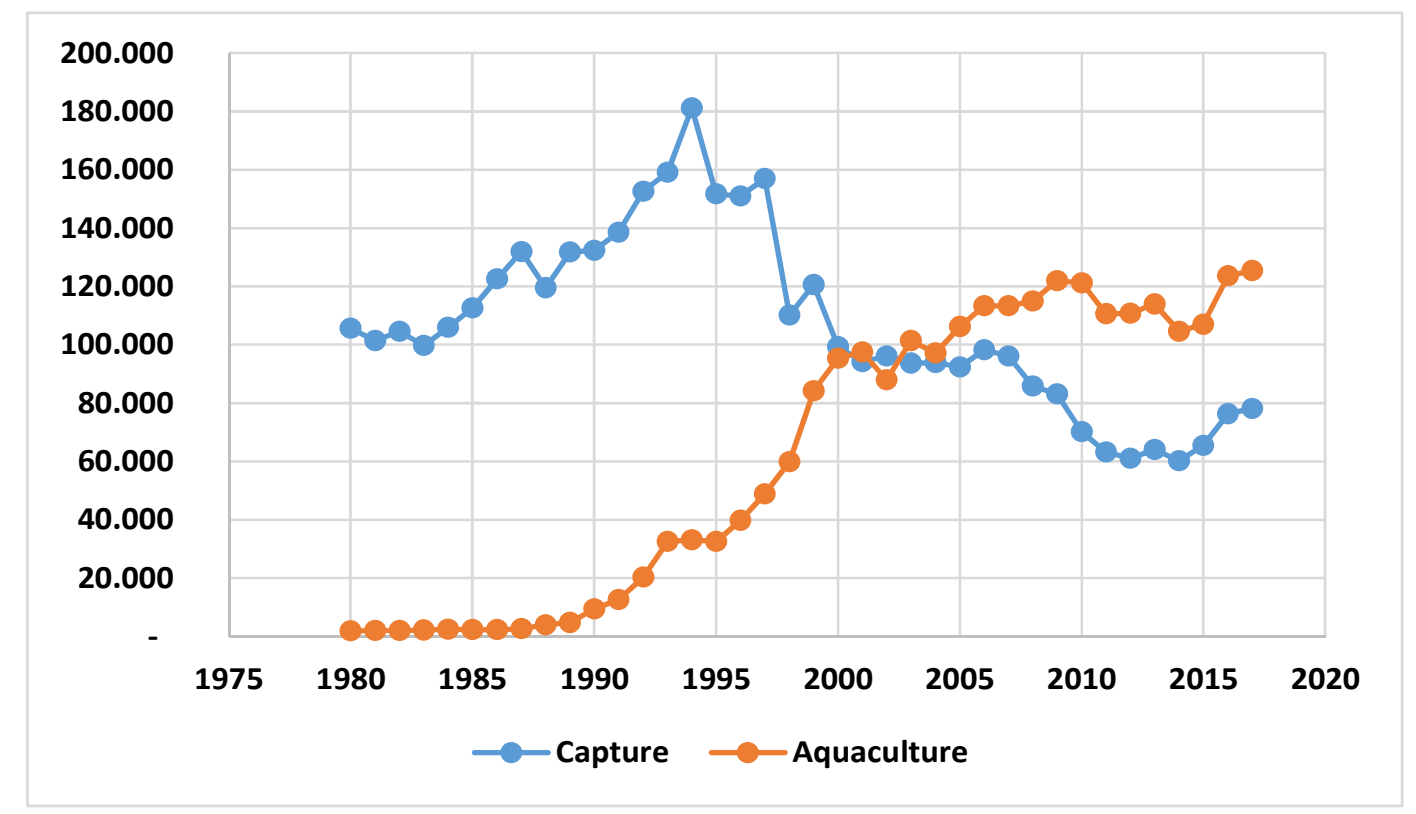

Figure A2. Total production of deep-sea fishing and aquaculture in Greece, 1980-2017 (in tonnes). Data Source: FARNET. Guide n 8: Marketing the local catch. European Commission, Directorate-General for Maritime Affairs and Fisheries, Director-General, 2014 and visualization by authors. 


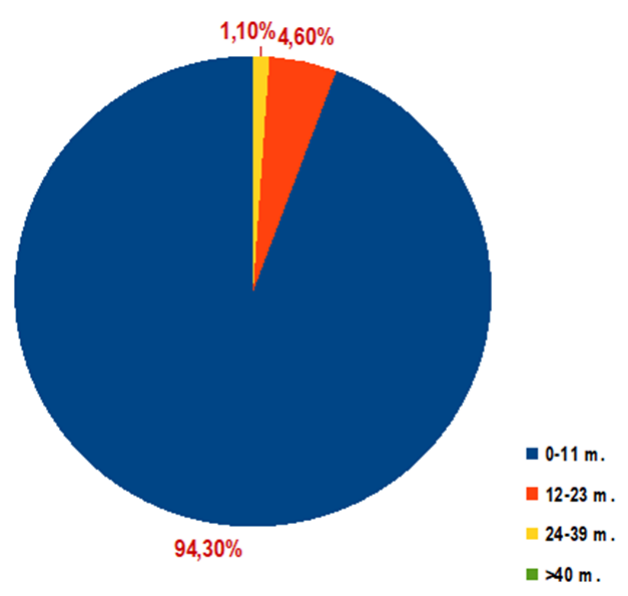

(a)

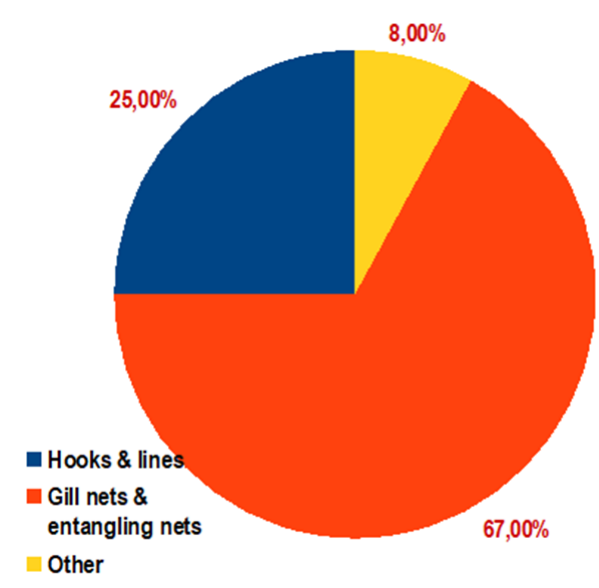

(b)

Figure A3. The Greek Fishing Fleet and Gear Composition. Source: xEUMOFA. Country Profile Greece; European Market Observatory for Fisheries and Aquaculture Products, 2019 [16], and visualization by authors.

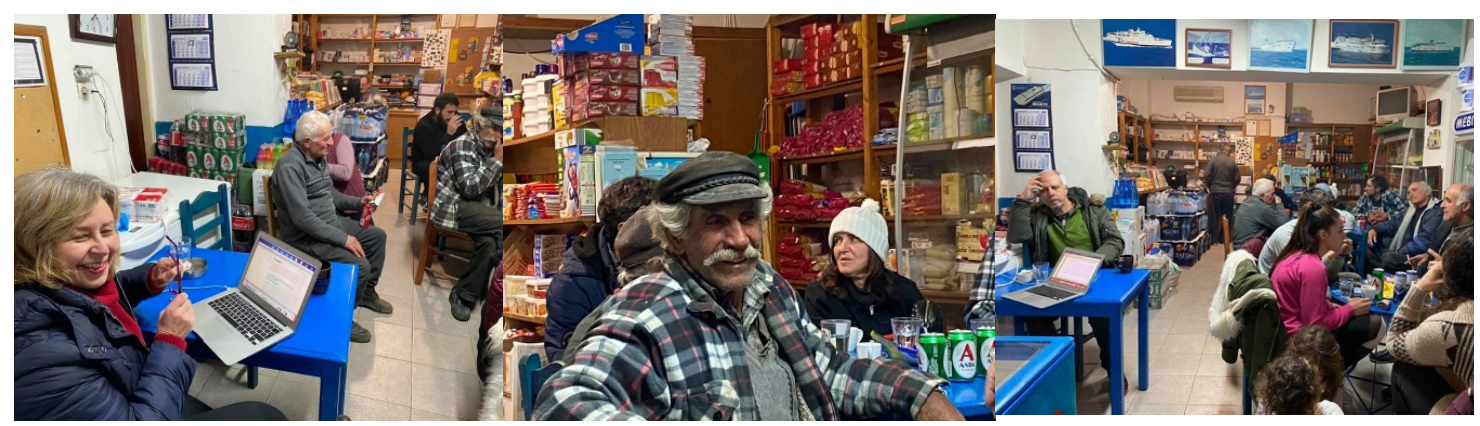

Figure A4. Face-to-face contacts and interviews with local fishermen in the Herakleia island in Small Cyclades.

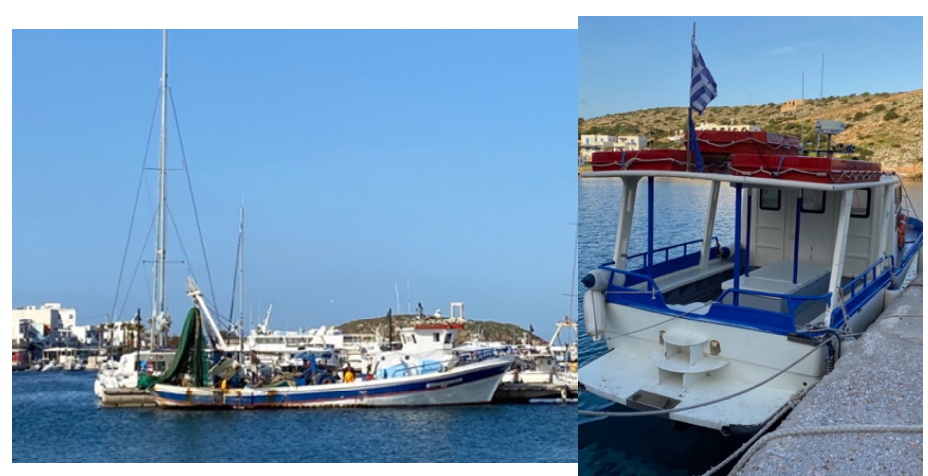

(a)

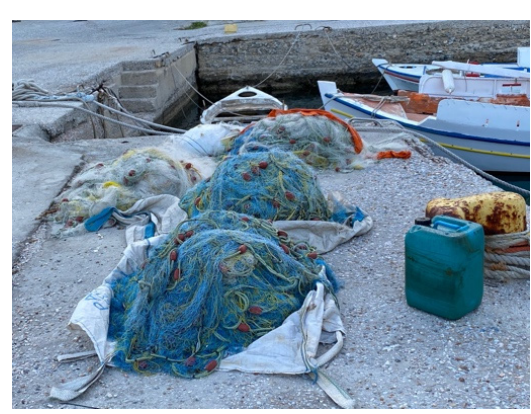

(c)

Figure A5. Artisanal fishing vessels in Naxos (a) and Herakleia (b) islands and (c) traditional fishing nets. 
Table A1. Fishing tourism enterprises in Greece, 2019.

\begin{tabular}{|c|c|c|}
\hline Region (NUTS2) & Regional Unit & Fishing Tourism Enterprises \\
\hline \multirow{4}{*}{ South Aegean (32.3\%) } & Naxos & 10 \\
\hline & Kalymnos & 3 \\
\hline & Syros & 13 \\
\hline & Rhodes & 24 \\
\hline \multirow{3}{*}{ Crete $(14.2 \%)$} & Heraklion & 5 \\
\hline & Lasithi & 5 \\
\hline & Chania & 12 \\
\hline Attica $(10.3 \%)$ & Attiki & 16 \\
\hline \multirow{4}{*}{$\begin{array}{l}\text { East Macedonia and Thrace } \\
\qquad(7.1 \%)\end{array}$} & Evros & 4 \\
\hline & Kavala & 3 \\
\hline & Rodopi & 3 \\
\hline & Xanthi & 1 \\
\hline \multirow{2}{*}{ Central Greece (6.45\%) } & Fthiotida & 3 \\
\hline & Evia & 7 \\
\hline \multirow{3}{*}{ Central Macedonia (5.81\%) } & Pieria & 2 \\
\hline & Halkidiki & 4 \\
\hline & Thessaloniki & 3 \\
\hline \multirow{3}{*}{ Ionian Islands (4.52\%) } & Kefallonia & 5 \\
\hline & Zakynthos & 1 \\
\hline & Lefkada & 1 \\
\hline Epirus (1.29\%) & Preveza & 2 \\
\hline North Aegean (3.87\%) & Mytiline & 6 \\
\hline \multirow{2}{*}{ Peloponnese (3.87\%) } & Messinia & 2 \\
\hline & Laconia & 4 \\
\hline \multirow{2}{*}{ Thessaly $(7.7 \%)$} & Larissa & 3 \\
\hline & Magnessia E Sporades & 9 \\
\hline \multirow{2}{*}{ Western Greece $(2.58 \%)$} & Ilia & 2 \\
\hline & Achaia & 2 \\
\hline Total & & 155 \\
\hline
\end{tabular}

Data Source: Ministry of Rural Development and Food, Directorate of Fishing Activity and Product Control, 2019 and own elaboration by authors. 
Table A2. Fisheries Local Action Groups (FLAGs) in Greece, 2017, Data Source: FARNET. Greece, Country Factsheet and own elaboration by authors.

\begin{tabular}{|c|c|c|c|c|c|c|c|}
\hline Code & FLAG Name & Region & Surface Area $\left(\mathbf{k m}^{2}\right)$ & Population & $\begin{array}{c}\text { Population } \\
\text { Density (per km²) }\end{array}$ & $\begin{array}{l}\text { Employment in } \\
\text { Fisheries } \\
\text { (Persons) }\end{array}$ & $\begin{array}{l}\text { Pescatourism as } \\
\text { Key Thematic } \\
\text { Direction of } \\
\text { FLAG's Strategy }\end{array}$ \\
\hline GR201 & Evros FLAG & \multirow{4}{*}{ East Macedonia -Thrace } & 329 & 6.773 & 21 & 54 & No \\
\hline GR202 & Rodopi FLAG & & 845 & 17.832 & 21 & 278 & No \\
\hline GR203 & Kavala City FLAG & & 117 & 58.790 & 500 & 306 & Yes \\
\hline GR204 & $\begin{array}{l}\text { Thassos and Kavala } \\
\text { prefecture FLAG }\end{array}$ & & 884 & 35.784 & 40 & 328 & Yes \\
\hline GR205 & Halkidiki FLAG & \multirow{4}{*}{ Central Macedonia } & 419 & 12.558 & 30 & 191 & Yes \\
\hline GR206 & East Thessaloniki FLAG & & 296 & 48.496 & 164 & 555 & Yes \\
\hline GR207 & West Thessaloniki FLAG & & 154 & 13.326 & 87 & 188 & Yes \\
\hline GR208 & Pieria FLAG & & 140 & 30.188 & 216 & 297 & No \\
\hline GR209 & Kozani FLAG & West Macedonia & 607 & 14.905 & 25 & 14 & No \\
\hline GR210 & $\begin{array}{l}\text { Ipeirios - Ioannina } \\
\text { FLAG }\end{array}$ & \multirow[t]{2}{*}{ Epirus } & 262 & 22.203 & 85 & 205 & No \\
\hline GR212 & $\begin{array}{c}\text { South Ipeiros } \\
\text { Amvrakikos FLAG }\end{array}$ & & 552 & 42.771 & 82 & 394 & No \\
\hline GR211 & Ionian Islands FLAG & \multirow[t]{2}{*}{ Ionian Islands } & 137 & 16.010 & 117 & 179 & Yes \\
\hline GR213 & Trixonida FLAG & & 1496 & 41.983 & 28 & 318 & No \\
\hline GR214 & Aitoliki FLAG & \multirow{3}{*}{ West Greece } & 856 & 57.034 & 67 & 505 & No \\
\hline GR215 & Ahaia FLAG & & 742 & 91.574 & 123 & 115 & No \\
\hline GR216 & Olympias FLAG & & 607 & 45.702 & 75 & 241 & Yes \\
\hline GR217 & Messinia FLAG & \multirow{2}{*}{ Peloponnese } & 282553 & 16.482 & 58 & 119 & Yes \\
\hline GR218 & Parnonas FLAG & & 1726 & 66.011 & 38 & 567 & Yes \\
\hline GR219 & Attiki island FLAG & Attica & 879 & 74.651 & 85 & 380 & Yes \\
\hline GR220 & $\begin{array}{c}\text { Central and North Evia } \\
\text { FLAG }\end{array}$ & \multirow[t]{2}{*}{ Central Greece } & 171981 & 90.463 & 53 & 578 & No \\
\hline GR221 & $\begin{array}{l}\text { South Evia \& Skyros } \\
\text { FLAG }\end{array}$ & & 154587 & 40.975 & 27 & 578 & Yes \\
\hline GR222 & Pillio FLAG & \multirow[t]{2}{*}{ Thessaly } & 303 & 15.151 & 50 & 224 & No \\
\hline GR223 & Lemnos FLAG & & 527 & 17.262 & 33 & 123 & Yes \\
\hline GR224 & Lesvos FLAG & \multirow{2}{*}{ North Aegean } & 1642 & 86.436 & 52 & 1295 & Yes \\
\hline GR225 & Chios FLAG & & 907 & 45.951 & 100 & 297 & No \\
\hline GR226 & Samos FLAG & \multirow{5}{*}{ South Aegean } & 781 & 42.859 & 55 & 950 & No \\
\hline GR227 & Dodecanese FLAG & & 2695 & 140.352 & 52 & 793 & Yes \\
\hline GR228 & Cyclades FLAG & & 2553 & 118.027 & 46 & 483 & No \\
\hline GR229 & Chania FLAG & & 691 & 30.126 & 44 & 106 & No \\
\hline GR230 & Rethymno FLAG & & 356 & 13.155 & 37 & 23 & Yes \\
\hline GR231 & $\begin{array}{c}\text { Crete Messara Gulf } \\
\text { FLAG }\end{array}$ & \multirow[t]{4}{*}{ Crete } & 275 & 10.840 & 39 & 16 & Yes \\
\hline GR232 & $\begin{array}{l}\text { Northern and South } \\
\text { East Crete FLAG }\end{array}$ & & 300 & 22.530 & 75 & 31 & Yes \\
\hline GR233 & Lassithi FLAG & & 1758 & 63.026 & 36 & 112 & No \\
\hline & Total & & & 1.450 .226 & & 10.843 & \\
\hline
\end{tabular}


Table A3. Typology of Multi-use of marine space according to Schupp et al. [34].

\begin{tabular}{cccc}
\hline Multi-Use Types & Space & Time & Type of Connectivity \\
\hline $\begin{array}{c}\text { Multi-purpose/ } \\
\text { multifunctional use. }\end{array}$ & $\begin{array}{c}\text { Uses share the same } \\
\text { water column. }\end{array}$ & Uses are synchronous. & $\begin{array}{c}\text { The main functions are } \\
\text { basically associated. }\end{array}$ \\
\hline Symbiotic use. & $\begin{array}{c}\text { Uses operate in the same } \\
\text { marine zone } \\
\text { (a connection exists in } \\
\text { the spatial dimension). }\end{array}$ & $\begin{array}{c}\text { Uses do not share the } \\
\text { same core infrastructure. }\end{array}$ & $\begin{array}{c}\text { Uses share some } \\
\text { common facilities } \\
\text { (transport, harbour etc.). }\end{array}$ \\
\hline Co-existence/co-location. & - & - & $\begin{array}{c}\text { Loose connectivity } \\
\text { between the } \\
\text { uses involved. }\end{array}$ \\
\hline $\begin{array}{c}\text { Succeeding } \\
\text { uses/repurposing. }\end{array}$ & $\begin{array}{c}\text { Uses are spatially } \\
\text { associated. }\end{array}$ & Uses are asynchronous. & $\begin{array}{c}\text { Fixed maritime } \\
\text { installations (e.g., oil and } \\
\text { gas platforms, offshore } \\
\text { wind farm) is changing } \\
\text { use after }\end{array}$ \\
& & decommissioning. \\
\hline
\end{tabular}

Source: Schupp et al., 2019 and own adjustments by authors.

\section{References}

1. FARNET. Guide $n$ 5: Diversification of Fisheries Areas; European Commission, Directorate-General for Maritime Affairs and Fisheries, Director-General (FARNET): Brussels, Belgium, 2011; Available online: https://webgate.ec.europa.eu/fpfis/cms/farnet/sites/default/files/documents/FARNET_Diversificationof-Fisheries-Areas-5_EN.pdf (accessed on 21 November 2019).

2. Nicolosi, A.; Sapone, N.; Cortese, L.; Laganà, V.; Marcianò, C. Sea Culture and Sustainable Development: Traditional Fishing Villages, Short Fish Supply Chain and Gastronomy in the Province of Reggio Calabria and the Archipelago of the Aeolian Islands (Italy). In Proceedings of the MIC 2015 Management International Conference, Portorož, Slovenia, 28-30 May 2015.

3. Said, A.; Chuenpagdee, R. Aligning the sustainable development goals to the small-scale fisheries guidelines: A case for EU fisheries governance. Mar. Policy 2019, 107. [CrossRef]

4. Schultz-Zehden, A.; Weig, B.; Lukic, I. Maritime Spatial Planning and the EU's Blue Growth Policy: Past, Present and Future Perspectives. In Maritime Spatial Planning; Zaucha, J., Gee, K., Eds.; Palgrave Macmillan: Basingstoke, UK, 2019.

5. Kyvelou, S.S.; Ierapetritis, D. Discussing and Analyzing “Maritime Cohesion" in MSP, to Achieve Sustainability in the Marine Realm. Sustainability 2019, 11, 3444. [CrossRef]

6. Jansen, H.M.; Van Den Burg, S.; Bolman, B.; Jak, R.G.; Kamermans, P.; Poelman, M.; Stuiver, M. The feasibility of offshore aquaculture and its potential for multi-use in the North Sea. Aquac. Int. 2016, 24, 735-756. [CrossRef]

7. Kannen, A. Challenges for Marine Spatial Planning In the Context of Multiple Sea Uses, Policy Arenas and Actors Based On Experiences From the German North Sea. Reg. Environ. Chang. 2014, 14, 2139-2150. [CrossRef]

8. Van den Burg, S.W.K.; Aguilar-Manjarrez, J.; Jenness, J.; Torrie, M. Assessment of the geographical potential for co-use of marine space, based on operational boundaries for Blue Growth sectors. Mar. Policy 2019, 100, 43-57. [CrossRef]

9. European Commission. Addressing Conflicting Spatial Demands in MSP, Considerations for MSP Planners Final Technical Study; European Commission: Brussels, Belgium, 2018; Available online: http://www.medblueconomyplatform.org/ wp-content/uploads/2019/08/addressing_conflicting_spatial_demands_in_MSP.pdf (accessed on 19 December 2019).

10. Calado, H.; Papaioannou, E.A.; Caña-Varona, M.; Onyango, V.; Zaucha, J.; Przedrzymirska, J.; Roberts, T.; Sangiuliano, S.J.; Vergílio, M. Multi-uses in the Eastern Atlantic: Building bridges in maritime space. Ocean Coast. Manag. 2019, 174, 131-143. [CrossRef]

11. Depellegrin, D.; Venier, C.; Kyriazi, Z.; Vassilopoulou, V.; Castellani, C.; Ramieri; EBocci, M.; Fernandez, J.; Barbanti, A. Exploring Multi-Use potentials in the Euro-Mediterranean sea space. Sci. Total Environ. 2019, 653, 612-629. [CrossRef] 
12. Linke, S.; Bruckmeier, K. Co-management in fisherie-Experiences and changing approaches in Europe. Ocean Coast. Manag. 2015, 104, 170-181. [CrossRef]

13. Kyvelou, S.S.I.; Ierapetritis, D.G. How to make blue growth operational? A local and regional stakeholders perspective in Greece. WMU J. Marit. Aff. 2019, 18, 249-280. [CrossRef]

14. DGMARE. Workshop in Small Sea Spaces, 15-16 March, 2018, Portorož, Slovenia. Available online: https://www.msp-platform.eu/events/workshop-msp-small-sea-spaces (accessed on 15 January 2020).

15. Garcia, S.M.; Allison, E.H.; Andrew, N.; Béné, C.; Bianchi, G.; De Graaf, G.; Kalikoski, D.; Mahon, R.L.; Orensanz, L. Towards Integrated Assessment and Advice in Small-Scale Fisheries: Principles and Processes; FAO Fisheries and Aquaculture Technical Paper No. 515; FAO: Rome, Italy, 2008.

16. FAO. The State of Mediterranean and Black Sea Fisheries; General Fisheries Commission for the Mediterranean: Rome, Italy, 2016; Available online: http://www.fao.org/3/a-i5496e.pdf (accessed on 15 January 2020).

17. General Fisheries Commission for the Mediterranean-GFCM. Regional Plan of Action for Small-Scale Fisheries in the Mediterranean and the Black Sea: A Common Commitment for the Future; GFCM: Rome, Italy, 2018; Available online: http://www.fao.org/gfcm/news/detail/en/c/1154586/ (accessed on 15 January 2020).

18. European Commission. Communication from the Commission to the European Parliament and the Council. Consultation on the Fishing Opportunities for 2017 under the Common Fisheries Policy, COM/2016/0396 Final; European Commission: Brussels, Belgium, 2016; Available online: https:/eur-lex.europa.eu/legal-content/ EN/TXT/PDF/?uri=CELEX:52016DC0396\&from=EN (accessed on 15 January 2020).

19. Reports of the Scientific, Technical and Economic Committee for Fisheries (STECF)—Monitoring the performance of the Common Fisheries Policy (STECF-16-05)—CORRIGENDUM to STECF-16-03; EUR 27758 EN, JRC 100945; Publications Office of the European Union: Luxembourg, 2016; 60 p.

20. FAO; General Fisheries Commission for the Mediterranean. Report of the Nineteenth Session of the Scientific Advisory Committee on Fisheries, Ljubljana, Slovenia, 16-19 May 2017; FAO Fisheries and Aquaculture Report/FAO No. R1209; FAO: Rome, Italy, 2017; Available online: http://www.fao.org/gfcm/reports/statutorymeetings/detail/en/c/901161/ (accessed on 22 November 2019).

21. European Commission. Facility for Regional Policy Dialogue on Integrated maritime Policy/Climate Change) Led by Atkins Global; European Commission: Brussels, Belgium, 2017; Available online: https://www.gov.il/ BlobFolder/generalpage/eu_union/he/Regional_Outcomes_from_National_Assessments.pdf (accessed on 20 December 2019).

22. Vasilakopoulos, P.; Maravelias, C.D.; Tserpes, G. The Alarming Decline of Mediterranean Fish Stocks. Curr. Biol. 2014. [CrossRef]

23. Piasecki, W.; Głabbiński, Z.; Francour, P.; Koper, P.; Saba, G.; Molina García, A.; Ünal, V.; Karachle, P.K.; Lepetit, A.; Tservenis, R.; et al. Pescatourism-A European review and perspective. Acta Ichthyol. Piscat. 2016, 46, 325-350. [CrossRef]

24. Prosperi, P.; Kirwan, J.; Maye, D.; Bartolini, F.; Vergamini, D.; Brunori, G. Adaptation strategies of small-scale fisheries within changing market and regulatory conditions in the EU. Mar. Policy 2019, 100, 316-323. [CrossRef]

25. Lai, M.B.; Cicia, G.; del Giudice, T. Pescatourism, a sustainable tourist experience. J. Clean. Prod. 2016, 133, 1034-1042. [CrossRef]

26. FARNET. Guide $n$ 9: Fisheries and Tourism: Creating Benefits for the Community; European Commission, Directorate-General for Maritime Affairs and Fisheries, Director-General (FARNET): Brussels, Belgium, 2014; Available online: https://webgate.ec.europa.eu/fpfis/cms/farnet/files/documents/FARNET_Fisheries_and_ Tourism-9_EN.pdf (accessed on 14 January 2020).

27. European Commission. Linking Fisheries to the Tourism Economy, Farnet Magazine; European Commission: Brussels, Belgium, 2013; Available online: https://webgate.ec.europa.eu/fpfis/cms/farnet/files/documents/ FARNET_Magazine_09_EN_0.pdf (accessed on 7 January 2020).

28. Khovanova-Rubicondo, K.M. Cultural Routes as a Source for New Kind of Tourism Development: Evidence from the Council of Europe's Programme. Int. J. Herit. Digit. Era 2012, 1, 83-88. [CrossRef]

29. PESCA: New Community Initiative for Fisheries and Fishery-Dependent Zones. Available online: https: //ec.europa.eu/commission/presscorner/detail/en/IP_94_128 (accessed on 11 November 2019).

30. Gallizioli, G. The Social Dimensions of the Common Fisheries Policy: A Review of Current Measures. In Social Issues in Sustainable Fisheries Management; Urquhart, J., Acott, T., Symes, D., Zhao, M., Eds.; Springer: Dordrecht, The Netherlands, 2014. 
31. Kyvelou, S. (Ed.) From Spatial Planning to Territorial Management: The Notions of Strategic Spatial Planning and Territorial Cohesion in Europe; KRITIKI: Athens, Greece, 2010; p. 344. (In Greek)

32. Bragado, J.F. Perspectives for the Development of Tourism Activities Related to Fishing, 2014. Available online: https:/www.patt.gov.gr/site/attachments/article/17556/160114_meleti.pdf (accessed on 11 November 2019).

33. FARNET. Greece, Country Factsheet. Available online: https://webgate.ec.europa.eu/fpfis/cms/farnet2/onthe-ground/country-factsheets/greek-clld-programme_en (accessed on 13 November 2019).

34. Zaucha, J.; Bocci, M.; Depellegrin, D.; Lukic, I.; Buck, B.; Schupp, M.; Caña Varona, M.; Buchanan, B.; Kovacheva, A.; Karachle, P.K.; et al. Analytical Framework (AF)_Analysing Multi-Use (MU) in the European Sea Basins; MUSES: Edinburgh, UK, 2016.

35. Schupp, M.F.; Bocci, M.; Depellegrin, D.; Kafas, A.; Kyriazi, Z.; Lukic, I.; Schultz-Zehden, A.; Krause, G.; Onyango, V.; Buck, B.H. Toward a Common Understanding of Ocean Multi-Use. Front. Mar. Sci. 2019, 6, 165. [CrossRef]

36. Zaucha, J. Can Classical Location Theory Apply to the Sea Space? In Maritime Spatial Planning; Zaucha, J., Gee, K., Eds.; Palgrave Macmillan: Basingstoke, UK, 2019.

37. DIRECTIVE 2014/89/EU of the European Parliament and of the Council of 23 July 2014 Establishing a Framework for Maritime Spatial Planning. Available online: https:/eur-lex.europa.eu/legal-content/EN/ TXT/PDF/?uri=CELEX:32014L0089\&from=EN (accessed on 15 January 2020).

38. Scottish Inshore Fisheries Integrated Data System (SIFIDS) Project. Available online: http://www.masts.ac. uk/research/emff-sifids-project/ (accessed on 11 November 2019).

39. Law 4546/2018: Incorporation into Greek Legislation of Directive 2014/89/EU Establishing a Framework for Maritime Spatial Planning and other Provisions; Greek Government Official: Athens, Greece, 2018.

40. Minutes of the Parliamentary Committee of Production and Trade on the Draft Law about Incorporation into Greek legislation of Directive 2014/89/EU Establishing a Framework for Maritime Spatial Planning and other Provisions, 30 May 2018. Available online: https:/www.hellenicparliament.gr/Koinovouleftikes-Epitropes/ Synedriaseis? search=on\&commission $=$ fd28d780-fc9a-44f8-af41-06a4503111ea\&fromDate=30/05/2018\& toDate $=30 / 05 / 2018 \& d r d S e s s i o n P e r i o d s=d d a 9 c 33 e-b 907-4356-a f 5 e-a 80000 d 9397 c$ (accessed on 11 December 2019). (In Greek).

41. SUPREME Project Supporting Maritime Spatial Planning in the Eastern Mediterranean. Available online: http://www.msp-supreme.eu (accessed on 20 December 2019).

42. FAO. FishStat 2019. Available online: http://www.fao.org/fishery/statistics/en (accessed on 14 February 2020).

43. European Market Observatory for Fisheries and Aquaculture Products (EUMOFA). Available online: https://www.eumofa.eu (accessed on 14 February 2020).

44. EUMOFA. Country Profile Greece; European Market Observatory for Fisheries and Aquaculture Products, 2019. Available online: https://www.eumofa.eu/en/greece (accessed on 1 November 2019).

45. FARNET. Guide n 8: Marketing the Local Catch. European Commission, Directorate-General for Maritime Affairs and Fisheries, Director-General, 2014. Available online: https://webgate.ec.europa.eu/fpfis/cms/farnet/ files/documents/FARNET_Marketing_the_Local_Catch-8_EN.pdf (accessed on 14 February 2020).

46. Archipelagos Institute of Marine Conservation. Available online: https://archipelago.gr/en/our-work/marineconservation/fisheries/ (accessed on 20 December 2019).

47. Kyvelou, S.S.; Gourgiotis, A. Landscape as Connecting Link of Nature and Culture: Spatial Planning Policy Implications in Greece. Urban Sci. 2019, 3, 81. [CrossRef]

48. Act 4582/2018: Thematic Tourism-Special forms of Tourism-Regulations on Modernising the Institutional Framework of Tourism and Tourism Education Sectors-Support of Tourism Entrepreneurship and other Provisions; Greek Government Gazette: Athens, Greece, 2018.

49. Ierapetritis, D.G.; Lagos, D. Building rural entrepreneurship in Greece: Lessons from lifelong learning programmes. Entrep. Soc. Cap. Gov. Dir. Sustain. Dev. Compet. Reg. 2012, 281-301. [CrossRef]

50. Ierapetritis, D.G.; Lagos, D.; Balomenou, C.K. Outlining the determinants of youth entrepreneurship in the Greek periphery. Int. J. Entrep. Small Bus. 2010, 11, 205-217. [CrossRef]

51. Ierapetritis, D.; Lagos, D. Assessing the educational needs of Greek farmers that desire to develop entrepreneurial activity in agritourism. Stud. Reg. Urban Plan. 2009, 12, 20.

52. Joint Ministerial Decision 414/2354/12.1.2015: Prerequisites, Terms and Procedure for Carrying out of Fishing Tourism Activities by Professional Fishermen; Greek Government Gazette 98/20-1-2015, Issue B; Greek Government Gazette: Athens, Greece, 2015. 
53. European Parliament Resolution of 4 July 2017 on the Role of Fisheries-Related Tourism in the Diversification of fisheries (2016/2035(INI). Available online: https://www.europarl.europa.eu/doceo/document/TA-8-20170280_EN.html (accessed on 14 January 2020).

54. Ministry of Rural Development and Food. Annual Fleet Report 2018; Directorate General of Fishing: Athens, Greece, 2019.

55. Ierapetritis, D.G. Social capital, regional development and innovation in Greece: An interregional analysis. Int. J. Innov. Reg. Dev. 2019, 9, 22-58. [CrossRef]

56. Gomei, M.; Bellia, R. WWF Principles for Sustainable Fishing Tourism; WWF Mediterranean Marine Initiative: Rome, Italy, 2019; Available online: wwfmmi.org/sustainablefishingtourism (accessed on 1 March 2020).

57. World Tourism Organization. Tourism and Culture Synergies; UNWTO: Madrid, Spain, 2018. [CrossRef]

58. Hellenic Center for Marine Research. Good Practices Collection in Maritime Economy for the Mediterranean Interreg MED Mistral Project. Available online: https://prototype.tee.gr/wp-content/uploads/2019/ 11/MISTRAL_Good-practices-collection-in-maritime-economy-for-the-Mediterranean.pdf (accessed on 20 December 2019).

59. Convention on Biological Diversity. Aichi Biodiversity Targets. Available online: https://www.cbd.int/sp/ targets/ (accessed on 5 February 2020).

60. Papadakis, N.; Kyvelou, S. Greek Islands in Crisis: Social Vulnerability and the Need for Integrated Territorial Development Strategies. Eur. Q. Political Attitudes Ment. 2017, 6, 67-88.

61. Krstić, B.; Krstić, M.; Đekić, I. Sustainability of Development and Growth-Crisis, distribution of income and inequality. Econ. Sustain. Dev. 2018, 2, 1-12.

62. Natale, F.; Carvalho, N.; Harrop, M.; Guillen, J.; Frangoudes, K. Identifying fisheries dependent communities in EU coastal areas. Mar. Policy 2013, 42, 245-252. [CrossRef]

63. Kyvelou, S. Toward quality marine landscape plans. In Proceedings of the 22nd Council of Europe Meeting of the Workshops for the implementation of the European landscape Convention and International Congress "Water, Landscape and Citizenship in the Face of Global Change", Seville, Spain, 14-16 March 2019.

(C) 2020 by the authors. Licensee MDPI, Basel, Switzerland. This article is an open access article distributed under the terms and conditions of the Creative Commons Attribution (CC BY) license (http://creativecommons.org/licenses/by/4.0/). 